\title{
Ring current simulations of the 90 intense storms during solar cycle 23
}

\author{
M. W. Liemohn ${ }^{1}$ and M. Jazowski ${ }^{1}$ \\ Received 9 June 2008; revised 1 October 2008; accepted 9 October 2008; published 31 December 2008.
}

[1] All of the intense magnetic storms (minimum Dst value of $<-100 \mathrm{nT}$ ) from solar cycle 23 (1996-2005) were simulated using the hot electron and ion drift integrator (HEIDI) model. The simulations were run using a $K p$-driven shielded Volland-Stern electric field, static dipole magnetic field, and nightside plasma data from instruments on the Los Alamos geosynchronous satellites. Of the 90 events, 79 had acceptable plasma boundary condition coverage (with main phase data gaps of $4 \mathrm{~h}$ or less) and are included in the analysis. Storms were classified according to their solar wind driver, and means and correlations were examined. It is found that for this model configuration, the HEIDI model was able to best reproduce the Dst time series for sheath-driven events with an average minimum $D s t^{*}$ from the simulations at or below the observed minimum $D s t^{*}$ value. CIR-driven events were the least reproducible class of storms, with simulated minimum $D s t^{*}$ values typically only half to two thirds of the observed minimum value. In general, there was a strong correlation between the observed and modeled minimums of $D s t^{*}$ and essentially no correlation between the observed minimum $D s t^{*}$ and the modeled-to-observed $D s t^{*}$ ratio. This implies that the size of the eventual storm is not a good indicator of whether this version of HEIDI will be able to accurately reproduce it; rather, a $\mathrm{Kp}$-driven HEIDI simulation is consistently on the low side of predicting storm intensity, except for sheath-driven events.

Citation: Liemohn, M. W., and M. Jazowski (2008), Ring current simulations of the 90 intense storms during solar cycle 23, J. Geophys. Res., 113, A00A17, doi:10.1029/2008JA013466.

\section{Introduction}

[2] Most numerical studies of the Earth's storm time ring current involve multiple simulations of a single event [e.g., Fok et al., 1995; Kozyra et al., 1998; Jordanova et al., 1998; Ebihara and Ejiri, 2000; Sazykin et al., 2002; Khazanov et al., 2003; Garner et al., 2004; Liemohn et al., 2004; Chen et al., 2006; Zhang et al., 2007a]. Some numerical ring current studies have compared the responses during two events [e.g., Alexeev et al., 1996; Liemohn et al., 1999; Daglis et al., 2003; Ganushkina et al., 2006], or three or four [e.g., Ebihara and Ejiri, 1998; Liemohn et al., 2001; Chen et al., 2003; Khazanov et al., 2004]. A few examine the numerical results for a slightly larger collection of storms, perhaps 6-10 events [e.g., Kozyra and Liemohn, 2003; Liemohn and Kozyra, 2003; Huang et al., 2006]. However, there has not been a study to systematically examine a large number of storms and statistically assess the model results against observations from these events.

[3] Data analysis studies, on the other hand, have long been statistical in nature. While individual storm case studies that bring together many data sets are certainly useful for elucidating complex physical interactions [e.g., Farrugia et al., 2002; Goldstein et al., 2005; Gurgiolo et

\footnotetext{
${ }^{1}$ Atmospheric, Oceanic, and Space Sciences Department, University of Michigan, Ann Arbor, Michigan, USA.

Copyright 2008 by the American Geophysical Union. 0148-0227/08/2008JA013466
}

al., 2005], the compilation and examination of observations from a large number of storm events is central to reducing the uncertainties arising from the natural variability of the inner magnetospheric system during highly disturbed times. In situ plasma data has been condensed into functional dependencies on various driving parameters, such as the Young et al. [1982] plasma sheet compositional density equations or the Tsyganenko magnetic field models [e.g., Tsyganenko, 1989, 1995]. More recently, large-scale data analysis efforts have yielded insights into the morphology and evolution of the ring current. For example, O'Brien and McPherron [2000] used 30 years of solar wind and Dst data to construct a storm intensity prediction algorithm. The Temerin and $\mathrm{Li}$ [2002, 2006] Dst prediction model is exceptionally good at reproducing the Dst time series from solar wind parameters. Several others have followed with other relationships between solar wind parameters and the Dst index [e.g., Thomsen et al., 1998; Huttunen et al., 2002; Wang et al., 2003; Gonzalez et al., 2007]. Ganushkina et al. [2000] analyzed Polar data to quantify the relationship between the convective and inductive electric fields in ring current injections. Pulkkinen et al. [2001] and Fu et al. [2001, 2002] generated new compositional density functions for the near-Earth plasma sheet relative to solar wind driving parameters, and Ohtani et al. [2006] complemented these with an analysis of composition as seen by the IMAGE spacecraft. Le et al. [2004] quantified the modification of the near-Earth currents as a function of storm intensity. Lavraud et al. [2005] superposed data from 
geosynchronous spacecraft to understand the formation of the superdense plasma sheet. Denton et al. [2005, 2006] and Zhang et al. [2006] similarly binned and grouped data from geosynchronous spacecraft as a function of storm size, solar cycle phase, and solar wind driver. The observed morphology of the hot ion distribution of the inner magnetosphere has been systematically characterized by Lui [2003] and Jorgensen et al. [2004]. Ilie et al. [2008] assessed the importance of reference time choice when conducting superposed epoch analyses of inner magnetospheric storm data. These are just a few of the successful uses of many years of data to statistically examine ring current dynamics during storms.

[4] By considering many storms together, it is possible to methodically extract the response of the inner magnetospheric system to different driving conditions. However, as mentioned, such a large-scale effort has not been undertaken from a numerical viewpoint. Still, there is much to be learned from such an investigation. By systematically varying the configuration of a ring current model and then simulating as many storm events as possible, it is then feasible to conduct a statistical analysis of the simulation results themselves. Some of this has already been started. For example, Liemohn et al. [2002] showed scatterplots of simulated ring current energy input and decay rates against empirically derived functions for these quantities. However, these modeled data points were extracted from only 4 storm events, chosen ad hoc for this particular study. Huang et al. [2006] is the closest study of relative size, in which 9 storm intervals and a 2-month storm-free interval were simulated with an MHD model and compared against in situ data.

[5] The present study addresses this gap by presenting an examination of ring current simulations for an entire solar cycle of intense storm events. The storms are then sorted according to their solar wind driving structure, and the differences between the data-model comparisons for each storm category is assessed. The model configuration for these simulations is rather simplistic, but still provides a new perspective on how the ring current behaves during intense storms.

\section{Storm Events}

[6] Zhang et al. [2007b, 2007c] presented the list of the intense storms during solar cycle 23 (1996-2005 inclusive). Specifically, they created a list of all of the storms that reached $-100 \mathrm{nT}$ or lower as a minimum Dst value (Dst is a globally averaged low-latitude magnetic perturbation index [Sugiura and Kamei, 1991]). They found 88 such events, and these were the focus of the two Coordinated Data Analysis Workshops (CDAWs) in the spring of 2005 and 2007. The Zhang et al. [2007b, 2007c] studies are one set of results from these workshops, and more are available in the recent special section of Geophysical Research Letters [e.g., Xie et al., 2008; Liemohn et al., 2008] and the Journal of Geophysical Research special section (of which this paper is a part). The idea for the present study arose from the discussions within the magnetospheric working group of these CDAWs.

[7] The storms for this study were taken directly from Zhang et al. [2007c], with a slight modification. Their list includes 88 events, while the list for the present study has been expanded to 90 . The two additional storms are those of 17 and 19 April 2002. These two storms are part of a large sequence of intense activity, in which the Earth had experienced 4 storms with $D s t_{\min }<-100 \mathrm{nT}$. The Zhang et al. list already includes the other two events, which peaked on 18 and 20 April 2002. The two events on 17 and 19 April were caused by the passage of sheath regions in front of ICMEs, and the ICMEs themselves caused the subsequent events on 18 and 20 April. They are designated as four separate events in this study because $D s t$ had recovered by more than $50 \mathrm{nT}$ back toward zero before the next storm event in the sequence began. In addition, the ring current model to be used below has been employed to analyze these April 2002 events in a number of studies, treating the storms of the 17th and 18th separately [Liemohn et al., 2004, 2005, 2007].

[8] Zhang et al. [2007b, 2007c] analyzed the solar sources of these events and identified the geoeffective components of the interplanetary structure causing the storm. The results of this part of their study (with the addition of the two extra April 2002 storms) are summarized in Table 1, listing the number of storms caused by each type of driver classification. The total is divided between two main categories, storms driven by corotating interaction regions (CIRs) and interplanetary coronal mass ejections (ICMEs). It is seen that the vast majority of intense storms in this epoch were driven by ICMEs ( 79 of the 90 total). The last four columns of Table 1 are subsets of this ICME total, further classifying the driver into the part of the ICME that caused the rapid decrease of the Dst index at Earth. In particular, the largest subgroup within the ICME driver class is that of magnetic clouds (33 of the 79), as the large and steady interplanetary magnetic field (IMF) found within these structures can reconnect with the Earth's field (if oriented correctly) and cause a large pressure imbalance within the magnetosphere (which drives the storm). This is congruent with other studies, which found that magnetic clouds are the most geoeffective structure of the solar wind for causing large magnetic storms at Earth [e.g., Gosling et al., 1991; Zhang et al., 2004, Huttunen and Koskinen, 2004; Zhang et al., 2008], as opposed to other structures like CIRs [e.g., Richardson et al., 2006; Borovsky and Denton, 2006].

[9] The next largest subclass within the ICME total is the sheath ahead of the ICME (22 of the 79), which can contain large fluctuations of the IMF as well as high solar wind densities. The final two categories are labeled ejection and complex, respectively. The first category refers to a storm being driven by the ICME itself (not its preceding sheath) but when the ICME was not identified as a magnetic cloud. The second category indicates that the storm was caused by multiple parts of the ICME (e.g., sheath and cloud) or that the driving structure contained interacting ICMEs with several geoeffective components. The number in these two subclasses (12 each) is very similar to the number of CIR-driven storms in this 10-year interval (11 of the 90).

\section{Model Description}

[10] The model to be used for this study is the Hot Electron and Ion Drift Integrator (HEIDI) code. First developed in the 1990s at the University of Michigan by 
Table 1. Event Totals With Respect to Driver Classification

\begin{tabular}{lccccccc}
\hline \multicolumn{8}{c}{ All } \\
& Events & CIR & ICME & Sheath & MC & Ejection & Complex \\
\hline Entire storm list & 90 & 11 & 79 & 22 & 33 & 12 & 12 \\
Good-data list & 79 & 10 & 69 & 21 & 26 & 11 & 11 \\
\hline
\end{tabular}

Fok et al. [1993], Jordanova et al. [1996], and Liemohn et al. [1999] as the ring current-atmospheric interaction model (RAM), it has undergone a major modification as it is being incorporated into the Space Weather Modeling Framework (SWMF); the Michigan version of this ring current model is being renamed to more accurately reflect its role within the coupled models of the SWMF. The model solves the gyration and bounce-averaged kinetic equation for the phase space density of each hot plasma species in the inner magnetosphere, taking into account convective and magnetic drift, Coulomb collisional scattering and energy decay, charge exchange, atmospheric precipitation, and flow out the dayside outer boundary. It has the ability to include pitch angle and energy diffusion by plasma waves, but these processes are omitted in the present study.

[11] For the simulations presented below, all of the simulations have the same configuration. They each have a numerical grid with 22 radial grid cells, 24 local time cells, 41 energy bins, and 71 pitch angle grid cells. The behavior of the two dominant ring current ion species, $\mathrm{H}^{+}$and $\mathrm{O}^{+}$, is simulated, with the outer boundary composition specified by the Young et al. [1982] empirical formula. The time step of the code is $20 \mathrm{~s}$, with the time-split numerical operators performed in reverse order every step for a 40-s cadence of second-order accuracy results. The magnetic field is taken to be a static dipole and the imposed electric field is a shielded Volland-Stern formula driven by the 3-h Kp index [Volland, 1973; Stern, 1975; Maynard and Chen, 1975]. Along the nightside outer boundary of HEIDI, plasma observations are used from the magnetospheric plasma analyzer (MPA) instruments [Bame et al., 1993] and the synchronous orbiting particle analyzer (SOPA) instruments [Belian et al., 1992] on board the geosynchronous satellites operated by Los Alamos National Laboratory (LANL). The measurements are compiled into a single time series, taken from whichever satellite on the nightside of the Earth has the highest ion density at a given moment. HEIDI is also coupled to the Ober et al. [1997] dynamic global core plasma model (DGCPM) for plasmaspheric densities and the Rairden et al. [1986] neutral hydrogen geocoronal model.

[12] Each of the 90 storms was simulated for a 4-day interval surrounding the time of the minimum Dst index. Specifically, each run was started at the beginning of the day prior to the Dst minimum, and then continued for 2 days after the day of the storm peak. This allowed HEIDI to reach an equilibrium state before the intense driving of the storm interval began, as well as allowing HEIDI to simulate most or all of the sometimes very long recovery phase of the storms.

[13] While this is a simplistic setup for the HEIDI code, it was chosen as a baseline configuration for the first version of this numerical experiment of simulating all of the intense storms for a solar cycle. Other, presumably more sophisticated, initial and boundary condition configurations will be used for subsequent simulations of the storm set, but for this first attempt, these rather easy and validated inputs were used to drive the ring current model. This simplification of the setup also means that the code runs faster than real time on a regular desktop workstation, typically completing a simulation of a 4-day interval in less than a day.

[14] A data availability criterion was imposed on the storm list for inclusion in this study. Specifically, there had to be good coverage of the MPA data during the main phase of the storm (i.e., during the rapid drop of Dst). MPA (and not SOPA) is considered here because most of the ring current energy content in the inner magnetosphere maps to this energy range (that is, less than $45 \mathrm{keV}$ ) at geosynchronous orbit [e.g., Liemohn and Kozyra, 2002]. The inputs for all 90 storms were manually examined to determine the goodness of the MPA data during each storm's main phase, and those with more than $4 \mathrm{~h}$ of data gap in this interval were excluded. The final tally of usable storm intervals is given in Table 1. It is seen that 11 of the 90 storms were dropped from consideration, most of these (7 of the 11) from magnetic cloud-driven events (the other 4 classifications each lost one event from their original total).

\section{Typical Ring Current Simulation Results}

[15] There are several kinds of ring current morphologies that can arise in the inner magnetosphere during different storm driving conditions. It is useful to show some of the typical simulation results from HEIDI. In particular, an example is shown for a single-dip storm from a fairly wellstructured magnetic cloud, a multiple-dip storm from the passage of a complicated interacting ICME structure in which several parts were geoeffective, and a CIR-driven storm in which the model performed rather poorly.

[16] The storm event on 15 May 1997 was associated with the passage of a magnetic cloud preceded by a sheath of shocked plasma. Figure 1 shows time series of the $K p$ index and the nightside plasma sheet density, as well as the observed and modeled $D s t^{*}$ values. $D s t^{*}$ is the corrected Dst index and is defined for this study as

$$
D s t^{*}=\frac{D s t-D_{M P}+D_{Q}}{C_{I C}}
$$

where $D_{\mathrm{MP}}$ is an estimate of the contribution from the magnetopause currents (based on the upstream solar wind dynamic pressure), $D_{Q}$ is a quiet time offset value, and $C_{\mathrm{IC}}$ is a correction factor for the contribution from induced currents within the Earth. The modeled $D s t^{*}$ time series comes from the Dessler-Parker-Sckopke relationship [Dessler and Parker, 1959; Sckopke, 1966],

$$
D s t_{D P S}^{*}[\mathrm{nT}]=-3.98 \cdot 10^{-30} E_{R C}[\mathrm{keV}]
$$

(hereinafter referred to as DPS).

[17] The main phase of the storm was initiated at around 0200 UT on 15 May, driven by a period of strongly southward IMF having a peak value of $-25 \mathrm{nT}$. $D s t^{*}$ reached a minimum value of $-90 \mathrm{nT}$, at $1300 \mathrm{UT}$, followed by a quick recovery due to a northward turning of the IMF. By inspection, in Figure 1, it can be seen that the model came very close to matching the depth of the observed $D s t^{*}$ 


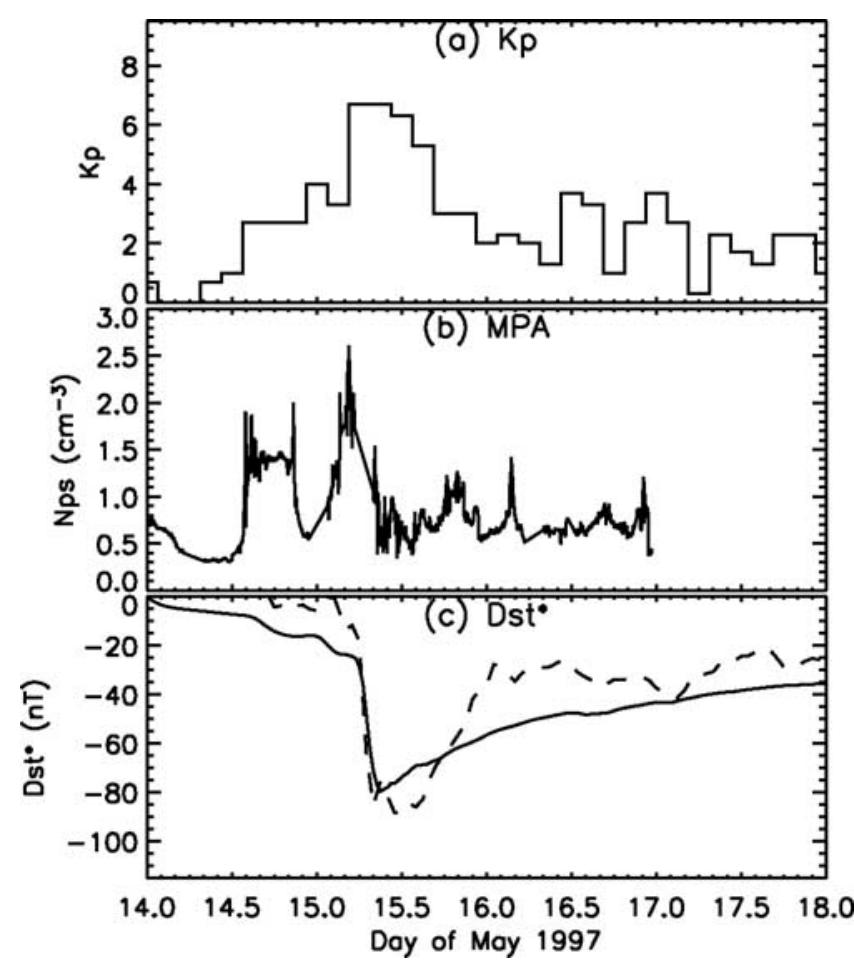

Figure 1. For the 15 May 1997 storm, shown here are (a) the 3-h $K p$ index, (b) the nightside near-Earth plasma sheet density from MPA data, and (c) the observed $D s t^{*}$ index (dashed line) with the modeled DPS-calculated $D s t^{*}$ time series (solid line).

peak, but not quite. $K p$ initially ramped up to 3 during the sheath passage, at which time there was a moderately strong near-Earth plasma sheet density of around $2 \mathrm{~cm}^{-3} . K p$ then jumped to a peak of 7 , just as the plasma sheet density increased from a midstorm low back up near $2 \mathrm{~cm}^{-3}$. The plasma sheet density quickly dropped again, however, while
$K p$ remained high. This resulted in an abrupt change from ring current growth to recovery, a few hours ahead of the observed minimum in $D s t^{*}$. From the two intervals of high source density, the resulting ring current distribution shows a distinct double-ring structure containing two trapped particle populations (see Figure 2). The model-data ratio and the root-mean-square (RMS) error of this ratio were 1.34 and 0.46 , respectively, for the entire 4-day window shown in Figure 1.

[18] Multiple sheath and ICME structures generated a particularly intense storm event on 31 March 2001. Figure 3 shows the $K p$ index, plasma sheet density, and observed and modeled $D s t^{*}$ time series for the event. The IMF was oriented strongly southward in the interval 0300 UT to $0700 \mathrm{UT}$, reaching an extreme value of $-45 \mathrm{nT}$. After a period of northward IMF, it again decreased to a peak value of $-35 \mathrm{nT}$ at around $1400 \mathrm{UT}$. As a result, there were multiple $D s t^{*}$ minima, having values of $-310 \mathrm{nT}$ and $-225 \mathrm{nT}$, at $0900 \mathrm{UT}$ and $2200 \mathrm{UT}$, respectively. Figure 3 indicates that the model closely reproduced the first observed $D s t^{*}$ minimum, but not the second. The model drivers, $K p$ and plasma sheet density, were both very high, producing an extensive interval of depressed simulated $D s t^{*}$. As can be seen in Figure 4, the resulting ring current injection was correspondingly intense during the initial main phase up to the peak. The model-data ratio and RMS error of this ratio were 0.92 and 0.37 , respectively (over the 4-day window). This indicates that even a simplistic model configuration can sometimes reproduce the observed intensity of the ring current [see also Jordanova et al., 2003a].

[19] The final example to be shown is the storm event of 8 May 2005, which was driven by a CIR. Figure 5 presents $D s t^{*}$ results for this storm, analogous to Figures 1 and 3 . The IMF was enhanced and southward in the interval 2100 UT on 7 May to 0300 UT on 8 May, reaching a peak value of $-16 \mathrm{nT}$. After a northward turning, the IMF again decreased to a peak value of $-14 \mathrm{nT}$ at around $1200 \mathrm{UT}$. As

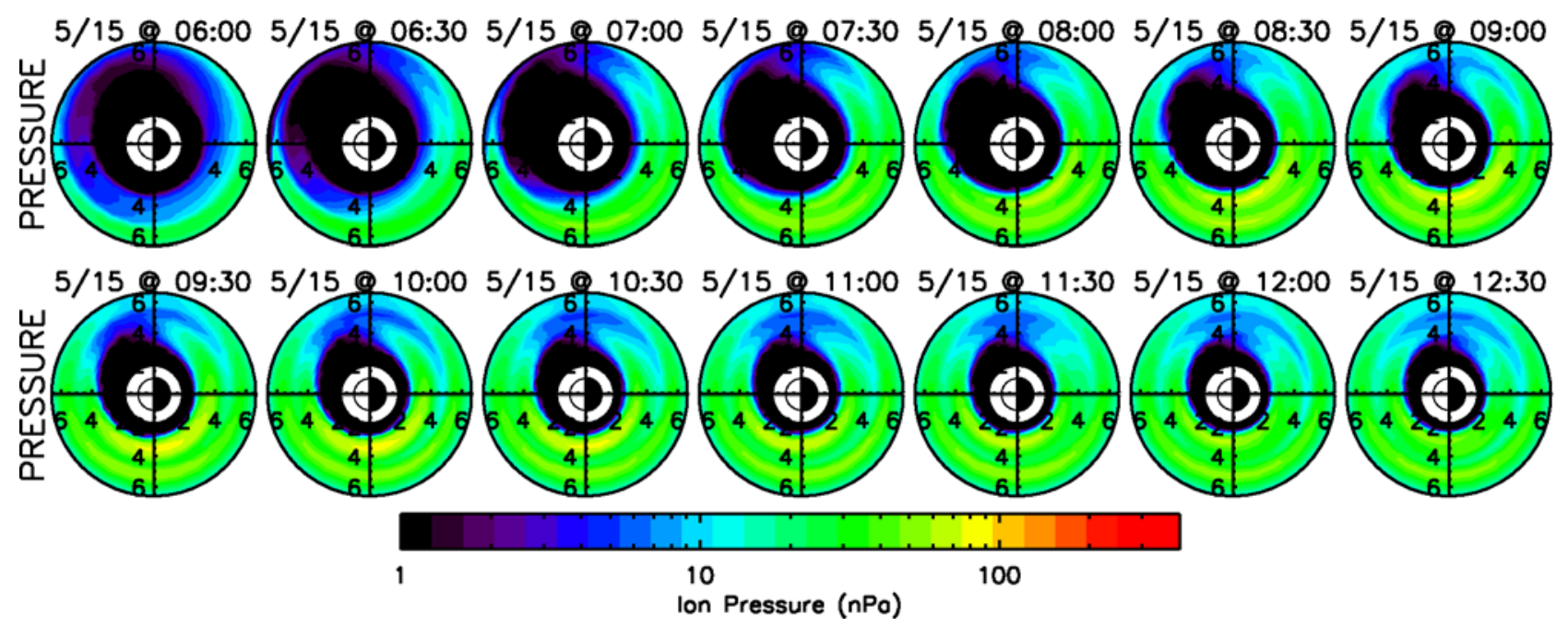

Figure 2. The modeled hot ion $\left(\mathrm{H}^{+}\right.$plus $\left.\mathrm{O}^{+}\right)$pressure distribution in the inner magnetosphere at 14 times during the 15 May 1997 storm (starting at 0600 UT on 15 May 1997 and then every 30 min until 1230 UT). The view is from over the North Pole with the Sun to the left. Distances are in Earth radii, with the results plotted in a region extending from $2 R_{E}$ to $6.5 R_{E}$. Note that the color scale is logarithmic. 


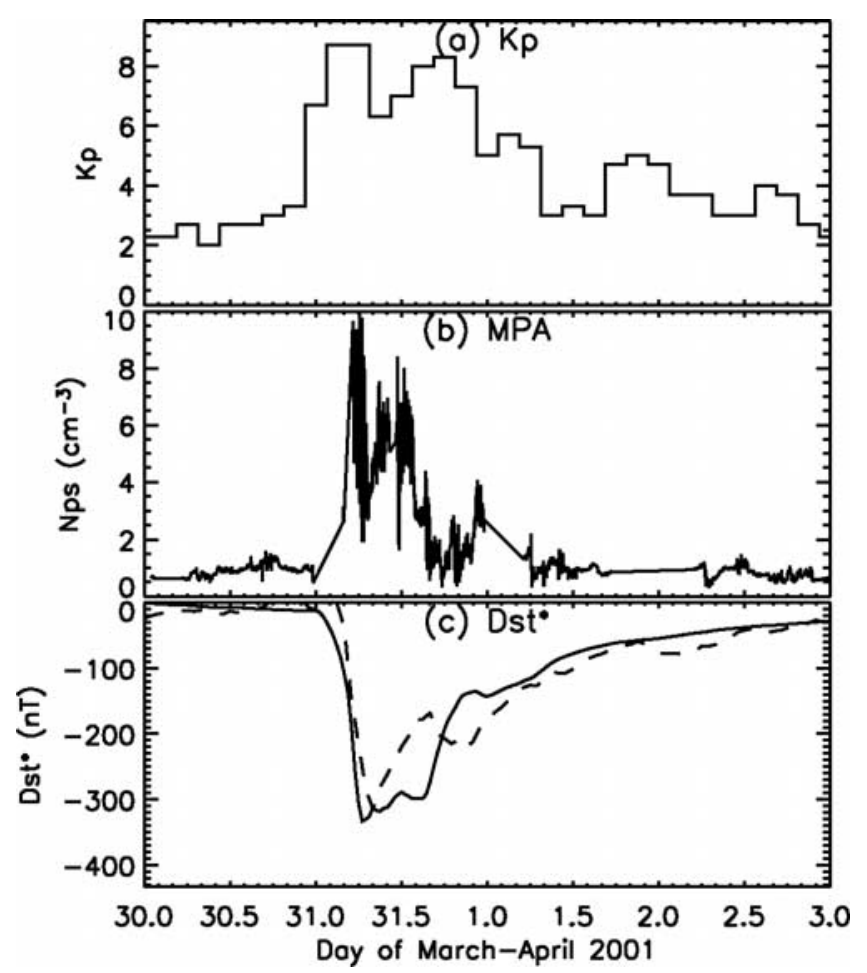

Figure 3. $(a-c)$ Like Figure 1 except for the 31 March 2001 storm. In Figure 3c the solid line is the model result, and the dashed line is the observed time series.

a result, there were two $D s t^{*}$ minima, having values of $-70 \mathrm{nT}$ and $-110 \mathrm{nT}$, at $0200 \mathrm{UT}$ and $1400 \mathrm{UT}$, respectively. As can be seen in Figure 5, the model did not accurately reproduce the observed $D s t^{*}$ minima. At the time of the first peak, $K p$ was relatively high, but the plasma sheet density was low, and there was little ring current intensification. Both $K p$ and the plasma sheet density were high around the second $D s t^{*}$ peak, but the modeled $D s t^{*}$ did not come close to the observed $D s t^{*}$. Figure 6 indicates that the resulting ring current was strong during the second main

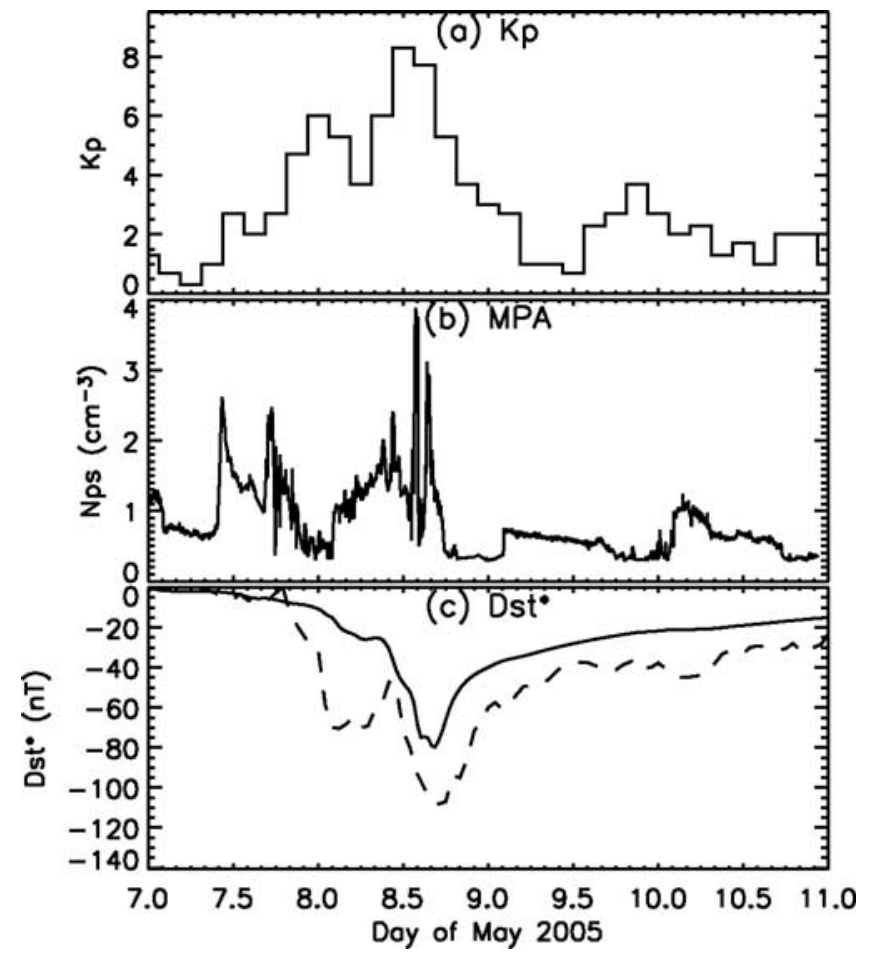

Figure 5. $(a-c)$ Like Figure 1 except for the 8 May 2005 storm. In Figure $5 \mathrm{c}$ the solid line is the model result, and the dashed line is the observed time series.

phase through the peak, exhibiting a slight double-ring form due to multiple plasma sheet density spikes throughout the interval. The model-to-data ratio between the $D s t^{*}$ time series and the RMS error of this ratio are 0.57 and 0.45 , respectively (over the 4-day interval shown in Figure 5).

\section{Statistics of the Simulation Results}

[20] Keeping these individual storm characteristics in mind, statistics from the entire event list can now be considered. First, it is useful to examine the average values

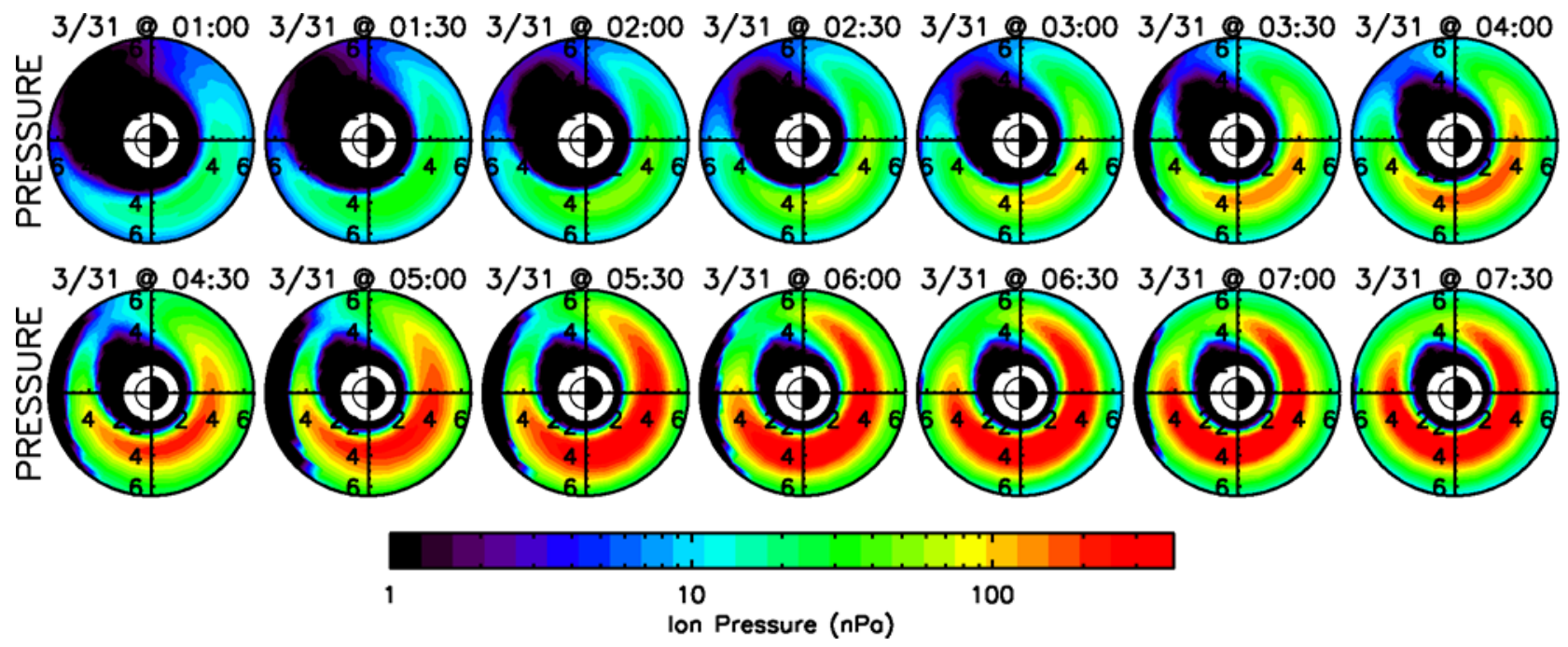

Figure 4. Like Figure 2 except for the 31 March 2001 storm. Pressures are plotted every $30 \mathrm{~min}$ from 0100 UT on 31 March 2001 to 0730 UT. 

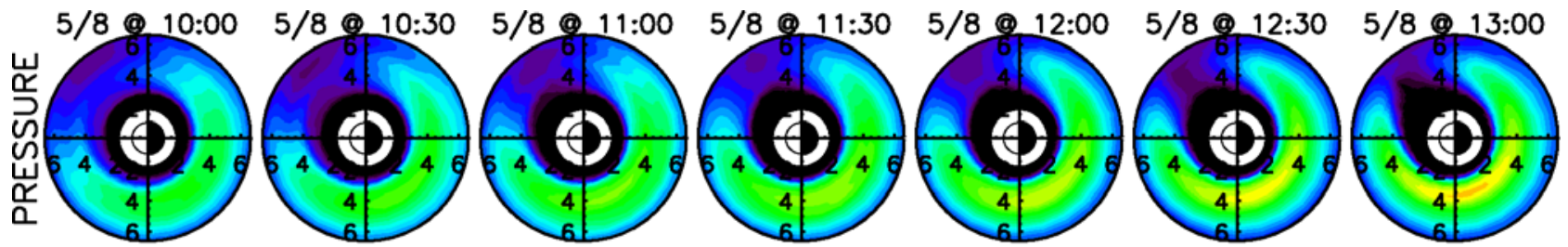

5/8 13:30
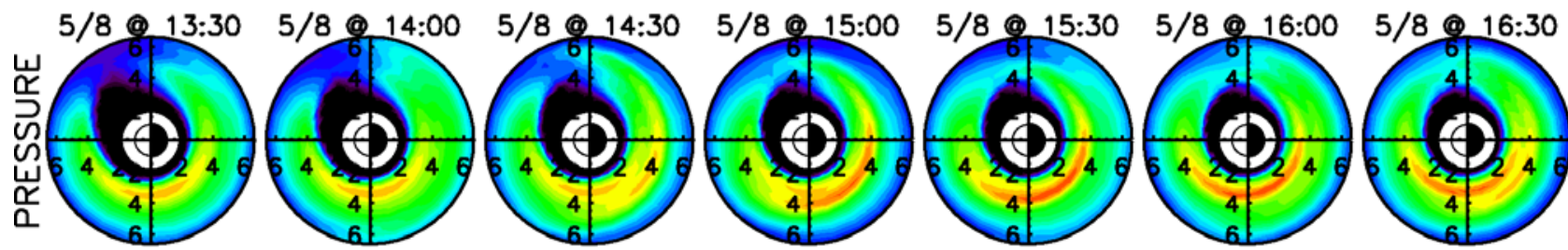

$5 / 8 @ 17: 00$
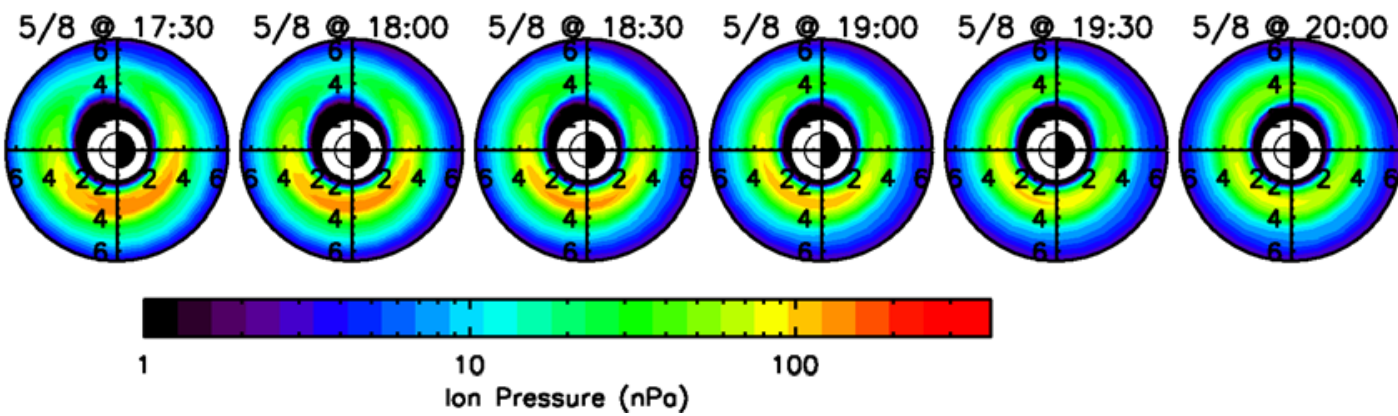

Figure 6. Like Figure 2 except for the 8 May 2005 storm. Pressures are plotted every 30 min from 1000 UT on 8 May 2005 to 2000 UT.

of the various input and output parameters from the HEIDI simulations. These averages are presented in Table 2, which lists average values for 16 parameters for the 7 classifications of the storms (as discussed above in section 2).

[21] The first 9 rows of Table 2 give average input values for the storms. The first row shows the average of $D s t^{*}{ }_{\text {min }}$. $D s t^{*}$ is presumably a measure of near-Earth currents, in particular removing the currents of the magnetopause and induction within the Earth. Because of the corrections applied to Dst in the conversion to $D s t^{*}$, the resulting $D s t^{*}$ is usually closer to zero than the original Dst time series. This is why the average $D s t^{*}{ }_{\text {min }}$ from the CIR-driven storms is actually greater than $-100 \mathrm{nT}$; the minimum values of the original Dst time series from these storms is, by definition from our storm selection criteria, less than $-100 \mathrm{nT}$. On average, the sheath-driven storms are the most intense events in the set.

[22] The remainder of the input values includes a second average. In addition to the averaging over the storms within the class, the values are also averaged over a 12-h interval that ends at the time of $D s t^{*}{ }_{\text {min. }}$. This time averaging was applied because the ring current takes many hours to adjust its position and intensity to reflect changing driving conditions. Ilie et al. [2008] found that the main phase of

Table 2. Average Values of Inputs and Results

\begin{tabular}{|c|c|c|c|c|c|c|c|}
\hline Parameter $^{\mathrm{a}}$ & All Events & CIR & $\mathrm{ICME}$ & Sheath & $\mathrm{MC}$ & Ejection & Complex \\
\hline$D s t_{\min }^{*}$ & -128.2 & -93.1 & -133.3 & -145.5 & -133.4 & -108.4 & -134.5 \\
\hline$\langle K p\rangle$ & 5.805 & 4.884 & 5.939 & 6.000 & 6.042 & 5.745 & 5.776 \\
\hline$\langle A\rangle^{\prime}$ & 0.794 & 0.577 & 0.825 & 0.847 & 0.843 & 0.789 & 0.778 \\
\hline$\left\langle F_{10.7}\right\rangle$ & 156.1 & 127.6 & 160.3 & 177.2 & 151.2 & 129.7 & 179.9 \\
\hline$\left\langle\left[\mathrm{O}^{+}\right] /\left[\mathrm{H}^{+}\right]\right\rangle$ & 0.659 & 0.354 & 0.703 & 0.850 & 0.668 & 0.439 & 0.770 \\
\hline$\left\langle N_{\text {MPA }}\right\rangle$ & 1.470 & 1.388 & 1.482 & 1.717 & 1.293 & 1.485 & 1.477 \\
\hline$\left\langle T_{\mathrm{MPA}}\right\rangle$ & 7.383 & 7.689 & 7.339 & 7.116 & 7.567 & 7.695 & 6.866 \\
\hline$\left\langle N_{\text {corr }}\right\rangle$ & 2.130 & 1.738 & 2.187 & 2.677 & 1.850 & 1.947 & 2.288 \\
\hline$\langle I\rangle$ & 1.996 & 1.099 & 2.126 & 2.722 & 1.832 & 1.801 & 2.010 \\
\hline $\mathrm{DPS}_{\min }$ & -100.4 & -51.8 & -107.5 & -143.9 & -84.2 & -91.6 & -108.8 \\
\hline $\mathrm{DPS} / D s t^{*}{ }_{\min }$ & 0.776 & 0.550 & 0.809 & 1.048 & 0.632 & 0.826 & 0.755 \\
\hline$\left\langle\mathrm{DPS} / D s t^{*}\right\rangle$ & 0.869 & 0.656 & 0.900 & 1.134 & 0.745 & 0.868 & 0.851 \\
\hline$P_{\max }$ & 216.6 & 101.1 & 233.3 & 337.6 & 174.1 & 189.0 & 218.5 \\
\hline$P_{\text {avg }}$ & 100.5 & 46.94 & 108.3 & 157.5 & 80.61 & 83.54 & 104.5 \\
\hline$P_{\max } / P_{\min }$ & 101.9 & 62.02 & 107.6 & 115.1 & 81.45 & 158.6 & 104.2 \\
\hline$\Delta P / P_{\text {avg }}$ & 2.100 & 2.041 & 2.108 & 2.075 & 2.082 & 2.197 & 2.147 \\
\hline
\end{tabular}

${ }^{\mathrm{a}}$ Quantities are averages of all events within that class. Parameters listed within brackets include an additional average over the 12 -h window preceding the time of minimum $D s t^{*}$. All others are averages of instantaneous values. 
Table 3. Correlation Coefficients Between $D s t^{*}$ and DPS

\begin{tabular}{llllllll}
\hline Parameter $^{\mathrm{a}}$ & All Events & CIR & ICME & Sheath & MC & Ejection & Complex \\
\hline $\mathrm{DPS}_{\min }$ & 0.704 & 0.791 & 0.685 & 0.695 & 0.845 & 0.347 & 0.753 \\
$\mathrm{DPS} / D s t^{*}{ }_{\min }$ & -0.029 & -0.541 & 0.021 & 0.201 & -0.011 & -0.006 & -0.464 \\
$\left\langle\mathrm{DPS} / D s t^{*}\right\rangle$ & -0.027 & 0.109 & 0.016 & 0.136 & 0.018 & 0.168 & -0.225 \\
\hline
\end{tabular}

${ }^{\mathrm{a}}$ The listed parameters are being correlated with the $D s t^{*}{ }_{\min }$ value for each event within each class.

intense storms at solar maximum is, on average, $12 \mathrm{~h}$ long. It is also the time interval chosen by Thomsen et al. [1998] for their input function analysis. Therefore, this time interval was chosen for the input function integrations presented in Table 2.

[23] The time-averaged input functions listed in Table 2 are as follows: 3-h Kp index; the Maynard and Chen [1975] $K p$-dependent activity parameter A

$$
A=\frac{0.045}{\left(1 .-0.159 K p+0.0093 K p^{2}\right)^{3}}\left[\frac{k V}{R_{E}^{2}}\right]
$$

the $\mathrm{F}_{10.7}$ solar flux index; the Young et al. [1982] $\mathrm{Kp}$ - and $\mathrm{F}_{10.7}$-dependent $\mathrm{O}^{+}$-to- $\mathrm{H}^{+}$ratio

$$
\zeta_{Y 82}=\frac{n_{O^{+}, Y 82}}{n_{H^{+}, Y 82}}=0.032 \exp \left(0.186 K p+0.011 F_{10.7}\right)
$$

(which is used as part of the simulation outer boundary condition); the nightside LANL MPA density and temperature applied at the outer boundary; a corrected MPA density value adjusted for the $\mathrm{O}^{+} / \mathrm{H}^{+}$ratio,

$$
n_{\text {corr }}=n_{M P A} \frac{1+\zeta_{Y 82}}{1+\frac{1}{4} \zeta_{Y 82}}
$$

(which can be up to a factor of 4 higher for pure $\mathrm{O}^{+}$ compared to pure $\mathrm{H}^{+}$); and a crude "total input function" $I$,

$$
\text { Input function }=I=A \cdot n_{\text {corr }}
$$

which is simply the multiplication of A with $\mathrm{n}_{\text {corr }}$ (and then averaged over the 12-h window and again over all of the storms in each category). This quantity is very similar to the input function of Thomsen et al. [1998], who used a 12-h average of the solar wind motional electric field times the nightside plasma sheet density, and found good correlation with the observed $D s t_{\min }$. The density values are in $\mathrm{cm}^{-3}$ and the temperatures are given in $\mathrm{keV}$.

[24] A clear difference is noticeable between the CIR and ICME driven storms. For ICME storms, the average $K p$ is a full point higher, $\mathrm{A}$ is $40 \%$ higher, $\mathrm{F}_{10.7}$ is more than $30 \mathrm{sfu}$ higher, the outer boundary $\mathrm{O}^{+}$to $\mathrm{H}^{+}$ratio is double, and $\langle I\rangle$ is $85 \%$ higher. This results in a $D s t^{*}{ }_{\text {min }}$ value that is over $40 \%$ deeper for the ICME storms. The exceptional subclass of the ICME events is the sheath-driven storms. For these events, the $\mathrm{F}_{10.7}$ value is 50 points higher than the CIR average, and the resulting $\langle I\rangle$ is nearly 2.5 times larger.

[25] These systematic differences in the input functions result in distinct outcomes from the HEIDI simulations. The final 7 rows of Table 2 show some highlights from these simulations. The variable named DPS is the $D s t^{*}$ equivalent number as calculated from the total energy content of the ring current simulation from the Dessler-Parker-Sckopke relation [Dessler and Parker, 1959; Sckopke, 1966]. While this is a crude approximation of the magnetic perturbation from the storm time ring current, and there are several glaring deficiencies in using this proxy [e.g., Carovillano and Siscoe, 1973; Liemohn, 2003], it is a useful diagnostic for interpreting the overall performance of the model at simulating the observed time sequence of a storm.

[26] In particular, the following values are presented for each of the 7 storm categories at the bottom of Table 2: the average minimum DPS value from each storm; the ratio of the DPS value to $D s t^{*}{ }_{\text {min }}$ at the time of $D s t^{*}{ }_{\min }$; the time average of DPS to $D s t^{*}$ for the $12 \mathrm{~h}$ preceding $D s t^{*}{ }_{\text {min }}$; the maximum hot ion pressure in the simulation $\left(\mathrm{P}_{\max }\right)$; the hot ion pressure averaged around all local times at the specific time and $\mathrm{L}$ shell of $\mathrm{P}_{\max }$ during each storm $\left(\mathrm{P}_{\mathrm{avg}}\right)$; the ratio between the maximum pressure and the minimum pressure around the local time ring at the same time and $\mathrm{L}$ shell as $P_{\max }\left(P_{\max } / P_{\min }\right)$; and the ratio of $P_{\max }-P_{\min }$ to $P_{\mathrm{avg}}$ $\left(\triangle P / P_{\text {avg }}\right)$. The $D s t$ and DPS values are given in nT while the pressure values are listed in $\mathrm{nPa}$.

[27] As with the inputs, there is an obvious difference in the simulation results between CIR-driven storms and ICME-driven storms. For the ICME storms, the average $\mathrm{DPS}_{\min }$ is over twice as deep, the DPS $/ D s t^{*}{ }_{\text {min }}$ and $\left\langle\mathrm{DPS} / D s t^{*}\right\rangle$ ratios are nearly $50 \%$ larger, and the average $\mathrm{P}_{\max }$ and $\mathrm{P}_{\mathrm{avg}}$ are over twice as large. It is clear that the differences in the drivers yielded a systematically larger ring current during ICME storms, as modeled by this version of HEIDI. Interestingly, however, the final entry in Table $2, \Delta \mathrm{P} / \mathrm{P}_{\mathrm{avg}}$, which is a measure of the anisotropy of the hot ion pressures in the inner magnetosphere, is nearly constant between the various storm classes. This is a function of the HEIDI configuration and not a true reflection of storm anisotropy invariance.

[28] The sheath-driven storms again stand out as a unique subclass within the ICME-driven storm category. This is the only category to exceed unity in the DPS/Dst* ratios, which it does for both the storm peak and 12-h averaged values. It is the only subcategory to exceed $250 \mathrm{nPa}$ in its $\mathrm{P}_{\max }$ average and $110 \mathrm{nPa}$ in its $\mathrm{P}_{\mathrm{avg}}$ value. However, this subcategory does not have the largest $\mathrm{P}_{\max } / \mathrm{P}_{\min }$ or $\Delta \mathrm{P} / \mathrm{P}_{\text {avg }}$ values, for which its values are rather average compared with the other storm categories.

[29] To determine how this version of the HEIDI model performed against the observed $D s t^{*}$ time series, it is necessary to look beyond the averages and instead consider correlation coefficients. Table 3 presents such values between $D s t^{*}$ min and various model result quantities from the DPS relation. A value of 1 or -1 would indicate perfect correlation (or anticorrelation), meaning a straight line exactly relates the values of the two quantities. Coefficients above (or, if negative, below) a certain significance threshold (which varies with the number of points in the correlation) can 
Table 4. Correlation Coefficient Significance Thresholds With Respect to Driver Classification

\begin{tabular}{lccccccc}
\hline & All Events & CIR & ICME & Sheath & MC & Ejection & Complex \\
\hline 5\% significance & 0.19 & 0.55 & 0.20 & 0.37 & 0.33 & 0.52 & 0.52 \\
$1 \%$ significance & 0.26 & 0.71 & 0.30 & 0.51 & 0.45 & 0.69 & 0.69 \\
\hline
\end{tabular}

be considered mathematically to be significantly correlated. That is, that the linearity between the two values is most likely not due to random chance. These correlation coefficient significance thresholds are shown in Table 4 for the $5 \%$ (significant) and $1 \%$ (highly significant) levels.

[30] In Table 3, only the top row (correlating $D s t^{*}{ }_{\text {min }}$ with DPS $_{\min }$ ) contains statistically significant relationships. Note that this correlation is highly significant (i.e., to the $1 \%$ level) for all but one of the categories, including the CIR-driven storms, which were the worst in terms of reproducing the actual value of $D s t^{*}$. The lower two rows show correlations between $D s t^{*}{ }_{\text {min }}$ and two different DPS/ $D s t^{*}$ ratios, and neither row contains a single value that is statistically significant.

[31] Table 5 is similar to Table 3, but contains correlations between DPS $_{\min }$ from the simulations and various input and output quantities (specifically, those listed in Table 2). For $\langle K p\rangle$ and $\langle\mathrm{A}\rangle$, the correlations with $\mathrm{DPS}_{\min }$ are only significant for some of the storm categories. Note that the correlation is not significant for either the CIR or the sheath-driven storm classes, but it is highly significant for the magnetic cloud class. Another input parameter is the 12-h averaged solar flux index $\left\langle\mathrm{F}_{10.7}\right\rangle$, which has a highly significant correlation with $\mathrm{DPS}_{\min }$ for the sheathdriven storms but not for the CIR or magnetic cloud-driven storm categories. Both $K p$ and $\mathrm{F}_{10.7}$ are used to calculate the $\mathrm{O}^{+} / \mathrm{H}^{+}$density ratio at the outer simulation boundary, and $\left\langle\mathrm{O}^{+} / \mathrm{H}^{+}\right\rangle$is highly significant for most of the ICME-driven subcategories (including sheath and MC storms) but not for the CIR-driven event class. Nearly every storm category is significantly correlated with the 12-h average of the plasma sheet density, as observed by the MPA instruments on the LANL satellites. However, $\left\langle T_{\mathrm{MPA}}\right\rangle$ is not well correlated with DPS ${ }_{\min }$. Applying the $\mathrm{O}^{+} / \mathrm{H}^{+}$compositional split to the LANL MPA moments yields a corrected outer boundary plasma density, and $\left\langle N_{\text {corr }}\right\rangle$ is highly correlated with DPS ${ }_{\text {min }}$ for most of the storm categories. Finally, when the convection activity parameter $\mathrm{A}$ is combined with the corrected density to produce a crude input function $I$ for the simulation, this function has a highly significant correlation with all of the storm event categories.

[32] Correlations between DPS $_{\min }$ and the various pressure quantities from Table 2 are also given in Table 5. Of these, $P_{\max }$ and $P_{\mathrm{avg}}$ have highly significant correlation coefficients with all of the storm categories. However, the other two pressure parameters, those that quantify the local time asymmetry of the ring current, are not well correlated with DPS $\min _{\min }$. The pressure ratio parameter shows no correlation for any category, while the $\Delta P / P_{\text {avg }}$ parameter is slightly better, with significant correlations for a few storm classes, including CIR and sheath-driven storms (but not magnetic cloud-driven events).

[33] Many other correlations were conducted, essentially comparing every parameter against all others for all storm categories. While the rest of these results will not be presented in tabular format, there are some interesting highlights that are worth mentioning. The $D s t^{*}$ ratio quantities (at the time of the storm peak at over a 12-h interval) are, for the most part, not significantly correlated against any of the input drivers or pressure parameters. For the correlations of the pressure quantities against the driving input parameters, $P_{\max }$ and $P_{\text {avg }}$ both show highly significant correlations against $\langle I\rangle$, as well as significant correlations against $\left\langle N_{\mathrm{MPA}}\right\rangle$ and $\left\langle N_{\text {corr }}\right\rangle$ for most storm categories. Only a few storm categories, however, have significant correlations between these pressure quantities and $\langle K p\rangle,\langle A\rangle,\left\langle\mathrm{O}^{+} / \mathrm{H}^{+}\right\rangle$, or $\left\langle T_{\mathrm{MPA}}\right\rangle$. The pressure asymmetry parameters are, for the most part, not correlated at all with any of the driver parameters.

\section{Discussion}

[34] Thus far, an objective presentation has been given of the types of ring current responses created in HEIDI and of the relationship between these results and various driving parameters and observations (for this numerical configura-

Table 5. Correlation Coefficients Between $\mathrm{DPS}_{\min }$ and Other Parameters

\begin{tabular}{|c|c|c|c|c|c|c|c|}
\hline Parameter $^{\mathrm{a}}$ & All Events & CIR & ICME & Sheath & $\mathrm{MC}$ & Ejection & Complex \\
\hline$\langle K p\rangle$ & -0.486 & -0.456 & -0.445 & -0.261 & -0.751 & -0.367 & -0.685 \\
\hline$\langle A\rangle$ & -0.516 & -0.505 & -0.476 & -0.336 & -0.767 & -0.428 & -0.626 \\
\hline$\left\langle F_{10.7}\right\rangle$ & -0.456 & 0.212 & -0.446 & -0.593 & -0.290 & -0.287 & -0.356 \\
\hline$\left\langle\left[\mathrm{O}^{+}\right] /\left[\mathrm{H}^{+}\right]\right\rangle$ & -0.658 & 0.080 & -0.640 & -0.736 & -0.659 & -0.335 & -0.758 \\
\hline$\left\langle N_{\text {MPA }}\right\rangle$ & -0.648 & -0.671 & -0.671 & -0.470 & -0.609 & -0.416 & -0.965 \\
\hline$\left\langle T_{\mathrm{MPA}}\right\rangle$ & 0.358 & -0.315 & 0.360 & 0.184 & 0.081 & 0.667 & 0.614 \\
\hline$\left\langle N_{\text {corr }}\right\rangle$ & -0.781 & -0.635 & -0.788 & -0.651 & -0.783 & -0.472 & -0.964 \\
\hline$\langle I\rangle$ & -0.835 & -0.893 & -0.825 & -0.728 & -0.868 & -0.675 & -0.962 \\
\hline$P_{\max }$ & -0.942 & -0.944 & -0.939 & -0.933 & -0.942 & -0.891 & -0.975 \\
\hline$P_{\text {avg }}$ & -0.950 & -0.936 & -0.948 & -0.941 & -0.926 & -0.898 & -0.980 \\
\hline$P_{\max } / P_{\min }$ & -0.322 & -0.556 & -0.300 & -0.400 & -0.329 & -0.771 & 0.331 \\
\hline$\Delta P / P_{\text {avg }}$ & -0.041 & -0.343 & -0.006 & -0.099 & -0.178 & -0.287 & 0.323 \\
\hline
\end{tabular}

${ }^{\mathrm{a}}$ The listed parameters are being correlated with the DPS ${ }_{\min }$ value for each event within each class. 

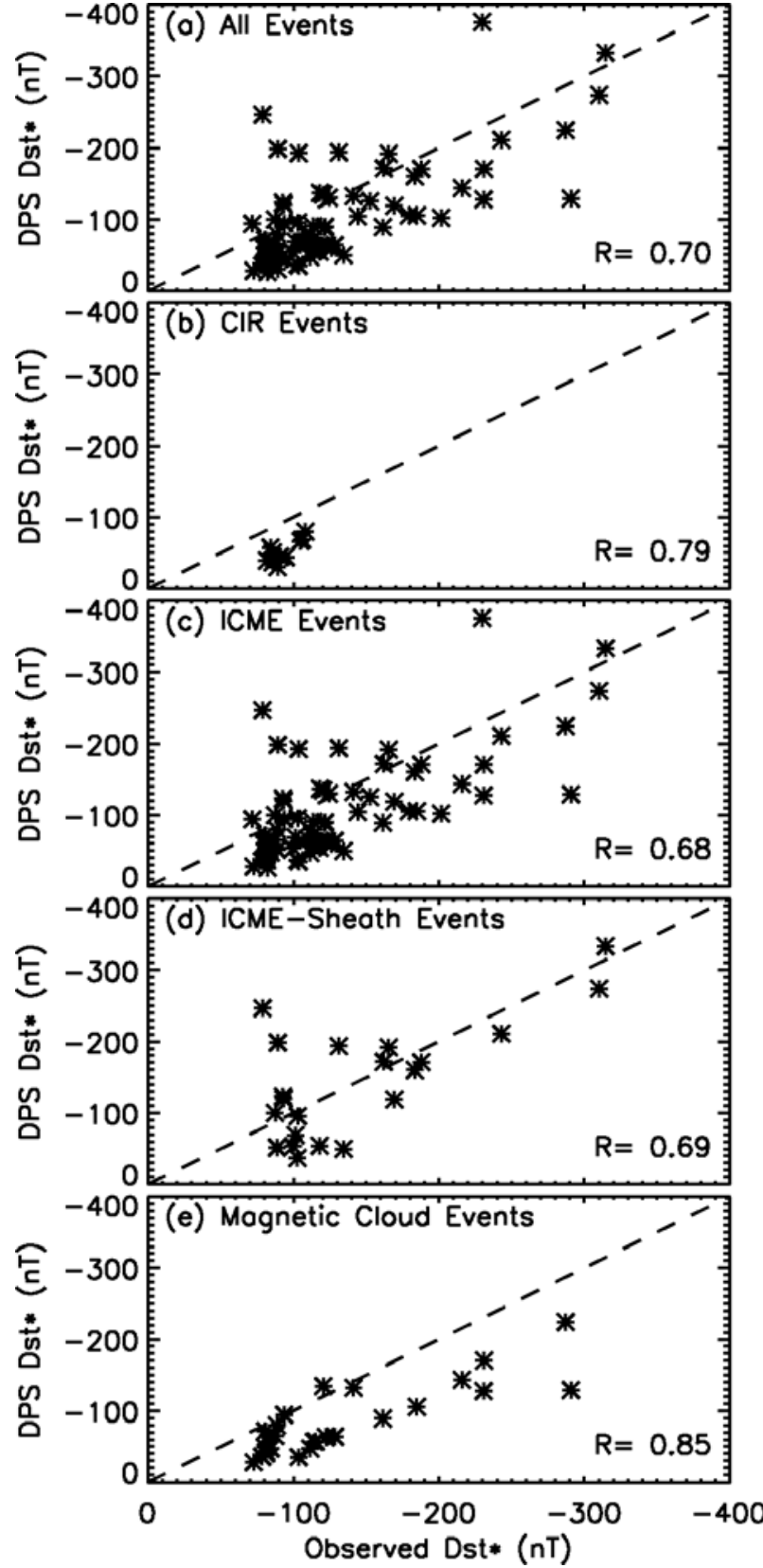

Figure 7. Scatterplots of the modeled $\mathrm{DPS}_{\min }$ value against the observed $D s t^{*}{ }_{\min }$ for each storm, for various storm driver categories: (a) all 79 valid events, (b) the 10 CIR-driven events, (c) the 69 ICME-driven events, (d) the 21 sheath-driven events, and (e) the 26 magnetic cloud-driven events. The linear correlation coefficient $R$ is given in the bottom right corner of each plot. The dashed line on each plot represents a perfect match between simulation and observation.

tion of the code). Below is a discussion of some of the implications from these results.

\subsection{Dst* Compared With DPS}

[35] Consider the relationship between the observed and simulated $D s t^{*}$ values. Because $D s t^{*}$ is an integrated measurement and DPS is an integrated calculation that have been roughly equated [e.g., Carovillano and Siscoe, 1973;
Greenspan and Hamilton, 2000; Liemohn, 2003], the comparison of these two quantities yields an overall goodness of fit for the simulation results. Figure 7 shows scatterplots of $D s t^{*}{ }_{\min }$ versus DPS ${ }_{\min }$ for each of the storms in 5 different categories. The dashed line indicates a perfect prediction between DPS $S_{\min }$ and $D s t^{*}{ }_{\min }$. Figure 7a shows a scatterplot for all 79 of the events, regardless of solar wind driver. Figures $7 \mathrm{~b}$ and $7 \mathrm{c}$ split this event list into CIR and ICME-driven storms, respectively. Note that the DPS $\mathrm{Sin}_{\min }$ and $D s t^{*}{ }_{\min }$ values for the CIR-driven storms are not particularly deep disturbances; there were no storms with $D s t^{*}$ below $-120 \mathrm{nT}$ that were driven by heliospheric corotating interaction regions. This shortfall of simulated ring current intensity compared with the observed value supports the finding of Jordanova [2006], in which a CIR and an ICME driven storm were simulated by a very similar code. They found that the model results were much better for the ICME-driven event than for the CIR-driven storm.

[36] The final two plots (Figures 7d and 7e) are subsets of Figure 7c, specifically those ICME-driven events where the predominant driver of geomagnetic activity was the sheath region ahead of the main ejection material (Figure 7d) or the ejection material itself when it has a special configuration, namely that of a magnetic cloud (Figure 7e). The other subsets of ICME-driven storms ("other ejecta" and "complex or multiple-part" drivers) have only a few storms in each category, and the statistics are rather poor. Therefore, scatterplots for these categories have been omitted from this presentation.

[37] All of the correlations in Figure 7 are highly significant, indicating a linear relationship, but the DPS ${ }_{\text {min }}$ values often fall below the perfect prediction level (dashed line). It appears, however, that the offset below this line is rather constant, indicating that the slope is near unity. The ratio of $\mathrm{DPS} / D s t^{*}{ }_{\min }$ was correlated with $D s t^{*}{ }_{\min }$ and listed in Table 3, with nearly all of the storm classes showing no correlation between these two quantities.

[38] A similar result is seen in Figure 8, which presents the 12-h average of the DPS/Dst ${ }_{\text {min }}$ ratio versus $D s t^{*}{ }_{\text {min }}$ for five storm categories. The result is the same, showing that the ratio is consistently shifted from unity regardless of the storm peak (for a given storm class). The correlation coefficients are nearly zero, indicating no relationship between this ratio and the storm peak intensity.

[39] The implication is that the VS-driven HEIDI model is a consistent predictor of the observed ring current strength during storms, regardless of the driver function and the accuracy of the prediction. That is, even for CIR driven storms, where HEIDI came up with only $60 \%$ of the observed Dst* values, the correlation between DPS and $D s t^{*}$ is highly significant. Lack of correlation between $D s t^{*}{ }_{\text {min }}$ and the DPS/Dst* ratios confirms this result, showing that the resulting ring current intensity from HEIDI is consistently shifted from the observed intensity. The conclusion is that the observed intensity $\left(D s t^{*}{ }_{\min }\right)$ is not a predictor of the goodness of fit for the HEIDI results. If anything, Figures 7 and 8 show that the spread of the results is greater for smaller storms, and HEIDI is a more precise ring current simulation tool for larger storm events.

[40] This conclusion is expected and consistent with earlier studies. In particular, Korth et al. [1999] conducted 

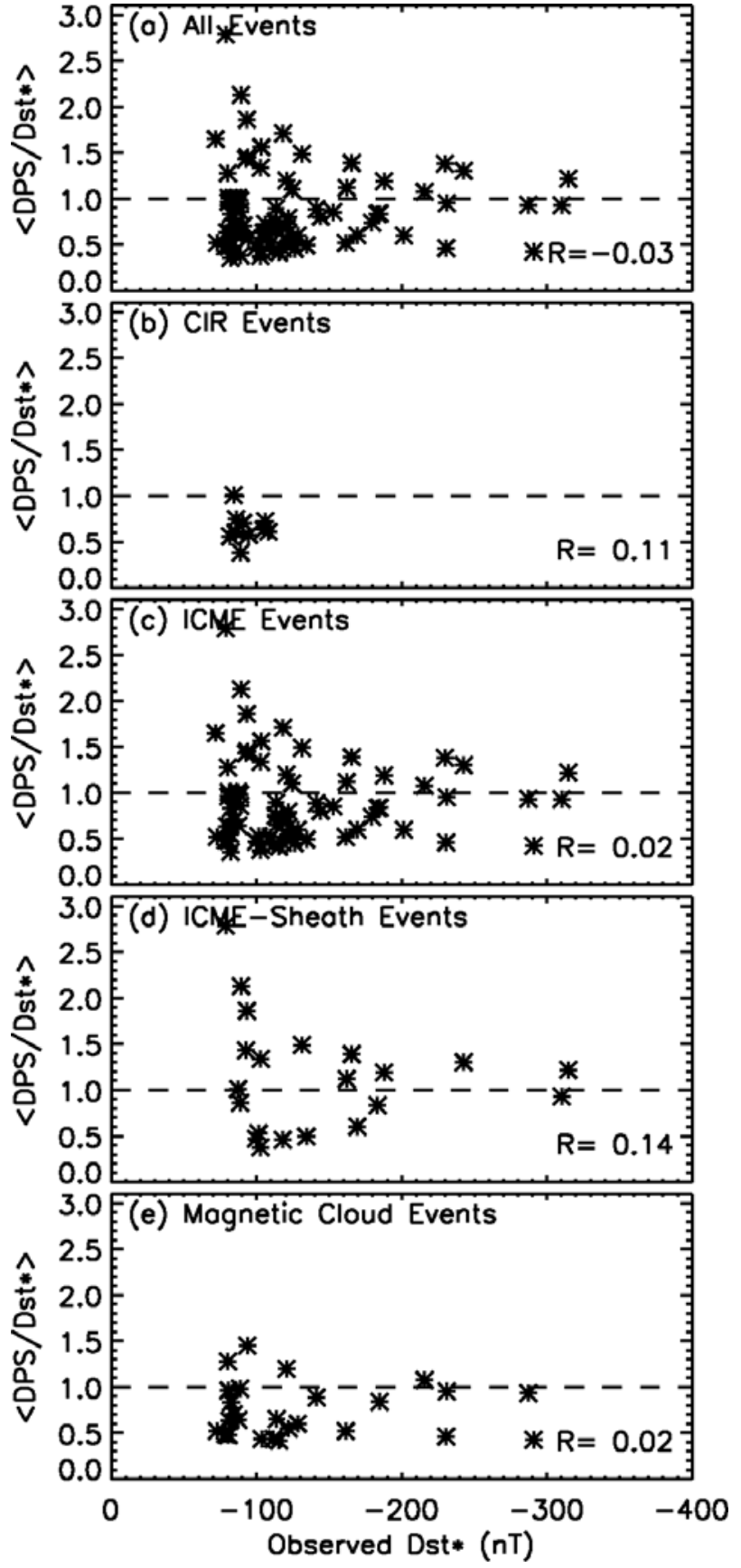

Figure 8. $(\mathrm{a}-\mathrm{e})$ Like Figure 7 except that the scatterplots are between the 12-h average of the DPS-to-Dst* ratio to the observed $D s t^{*}{ }_{\text {min }}$ for each event (the ratio is averaged over the $12 \mathrm{~h}$ prior to $\left.D s t^{*}{ }_{\min }\right)$. A dashed line is plotted on each panel at a ratio of unity.

an extensive analysis of geosynchronous orbit plasma data, showing that the shielded Volland-Stern electric field was one of the better models for describing the flow of plasma through the inner magnetosphere (of those in the study). Similarly, Thomsen [2004] showed that $K p$ is a reasonable measure of magnetospheric convection intensity. This statistical data-model comparison shows that this version of HEIDI is a relatively good predictor of the eventual size of the ring current during a magnetic storm, as has been found by others [e.g., Jordanova et al., 1998, 2003a; Liemohn et al., 1999, 2006].

[41] Another result from Figures 7 and 8 is that this version of HEIDI is systematically better at reproducing the $D s t^{*}{ }_{\text {min }}$ value for ICME-sheath-driven storms, relative to other storm classes. That is, examination of the spread of the points around the perfect fit line (dashed line in each panel of Figures 7 and 8) show that Figures $7 d$ and $8 d$ are better centered around this line compared to the points in all of the other panels. It can be inferred, then, that the inner magnetosphere is, in general, better simulated by this model setup during this class of storm events than during other storm events, and that the simulation input drivers used in this present configuration are systematically too low for the other storm categories. Thus, the Volland-Stern electric field description is best suited for simulating sheath-driven storm events rather than storms with other types of driving structures in the solar wind.

[42] It could be argued that the model setup might be reasonable for CIR-driven events, if only there were more intense events in this category. While this is certainly a possibility, there were no such events for solar cycle 23 and all of the CIR-driven storms have $D s t^{*}{ }_{\text {min }}$ values between $-70 \mathrm{nT}$ and $-110 \mathrm{nT}$. The intensity of all 10 of the CIRdriven storms is underpredicted by this version of HEIDI. A similar trend is true regarding magnetic cloud-driven events. For storms with $D s t^{*}{ }_{\text {min }}$ in this same range, 11 of the 12 storms are underpredicted by the model, and the single overprediction is by less than $1 \mathrm{nT}$. In contrast, the intensity of nearly half (5) of the 11 sheath-driven storms with $D s t^{*}{ }_{\min }$ in this range is overpredicted by the model. The implication of this is that the magnetosphere is responding differently to these different types of solar wind drivers, and this numerical setup for HEIDI is better at simulating the sheath-driven storms.

\subsection{DPS Compared With the Drivers}

[43] Another useful comparison to explore is the relationship between the simulated ring current intensity $\left(\mathrm{DPS}_{\min }\right)$ and the ring current drivers. In an examination of several case studies, Kozyra and Liemohn [2003] concluded that there are two primary drivers for the ring current, specifically the strength of the convection and the density of the near-Earth plasma sheet. Without one or both of these drivers, there will not be significant ring current enhancement. In fact, Liemohn and Kozyra [2005] demonstrated that convection without a plasma source actually leads to a rapid loss of ring current intensity.

[44] Figures 9 and 10 show scatterplots of the 12-h averaged $K p$ and MPA density versus the resulting DPS min $_{\text {value }}$ for each storm in 5 different categories. The $K p$ plots in Figure 9 appear to have a kink in the slope around a DPS of $-75 \mathrm{nT}$, below which there is a strong dependence on $K p$ while above which there is very little. This is because intense convection within the magnetosphere (as measured here by the $K p$ index) is only part of the necessary conditions for creating a large geomagnetic storm. Interestingly, this breakpoint in the convection dependence of eventual storm intensity is evident for all storm categories (except the CIR-driven storm class, which has only 1 event above the threshold, and a trend cannot be seen). This consistency between the storm categories implies that this 

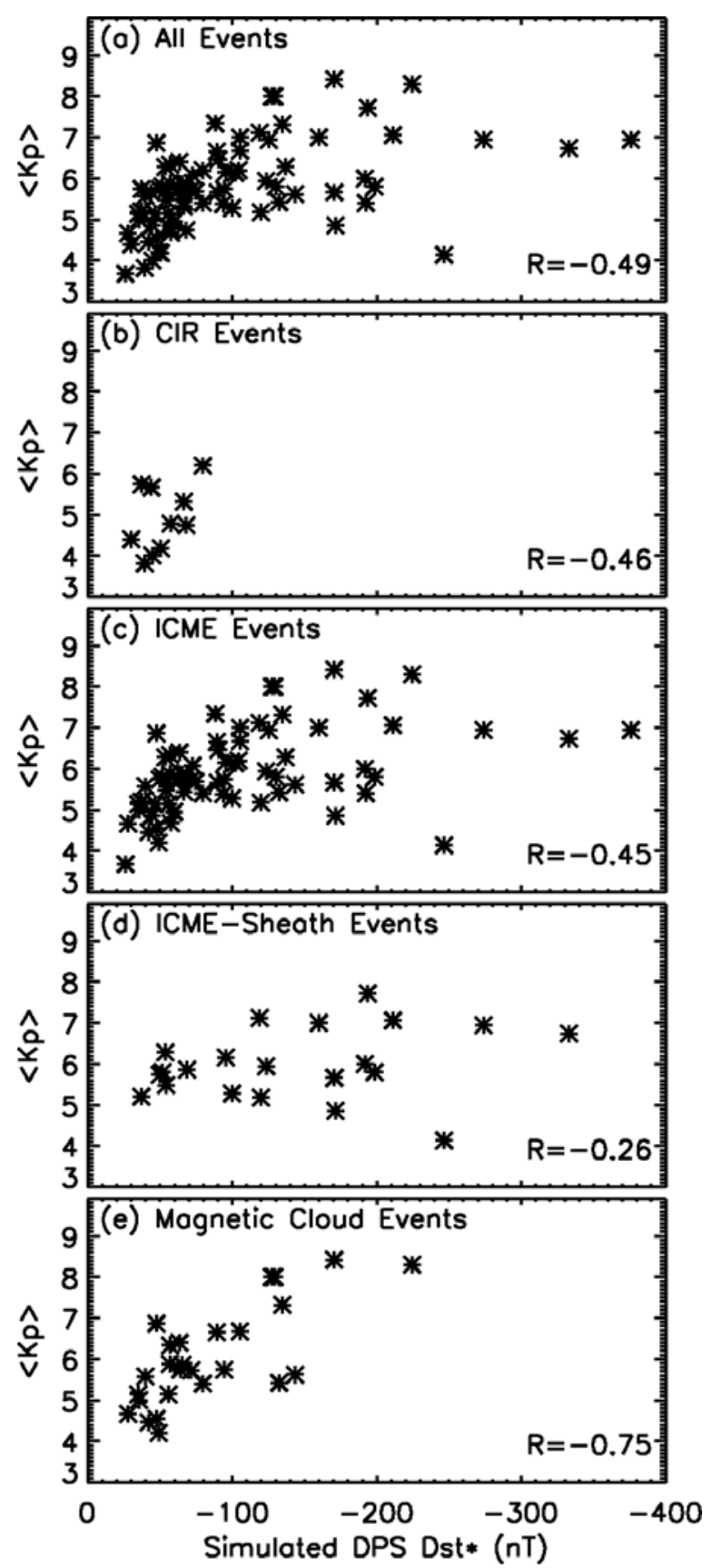

Figure 9. $(\mathrm{a}-\mathrm{e})$ Like Figure 7 except that the scatterplots are between the 12-h averaged $K p$ index and the simulated $\mathrm{DPS}_{\text {min }}$ for each storm.

dependence is a fundamental property of the storm time dynamics of the inner magnetosphere.

[45] An analysis of the other main driver of the ring current is shown in Figure 10, comparing the nightside MPA density to the resulting ring current intensity. The correlation coefficients for $\left\langle\mathrm{N}_{\mathrm{MPA}}\right\rangle$ are higher, and indeed all of them reach the $5 \%$ significance level. However, as with $K p$, much of the variation in DPS $_{\text {min }}$ is still not explained by this parameter alone, and the spread in density appears to increase with storm intensity. It is clear that there is another factor driving the ring current.
[46] Part of this can be corrected by considering the relative composition of the near-Earth plasma sheet, as given by the Young et al. [1982] formula. Figure 11 shows this comparison between $\left\langle\left[\mathrm{O}^{+}\right] /\left[\mathrm{H}^{+}\right]\right\rangle$and $\mathrm{DPS}_{\min }$ for 5 of the storm categories. This plot shows an uncorrelated cluster of points below a composition ratio of 1 for storms with DPS $_{\text {min }} \geq-170 \mathrm{nT}$, and then a small number of more intense events with higher composition ratios. In fact, all of the events with DPS $_{\min }<-200 \mathrm{nT}$ have a 12-h averaged composition greater than 1 , indicating $\mathrm{O}^{+}$dominance in the source of the ring current. The result implies that plasma sheet composition does not play much of a role, except that
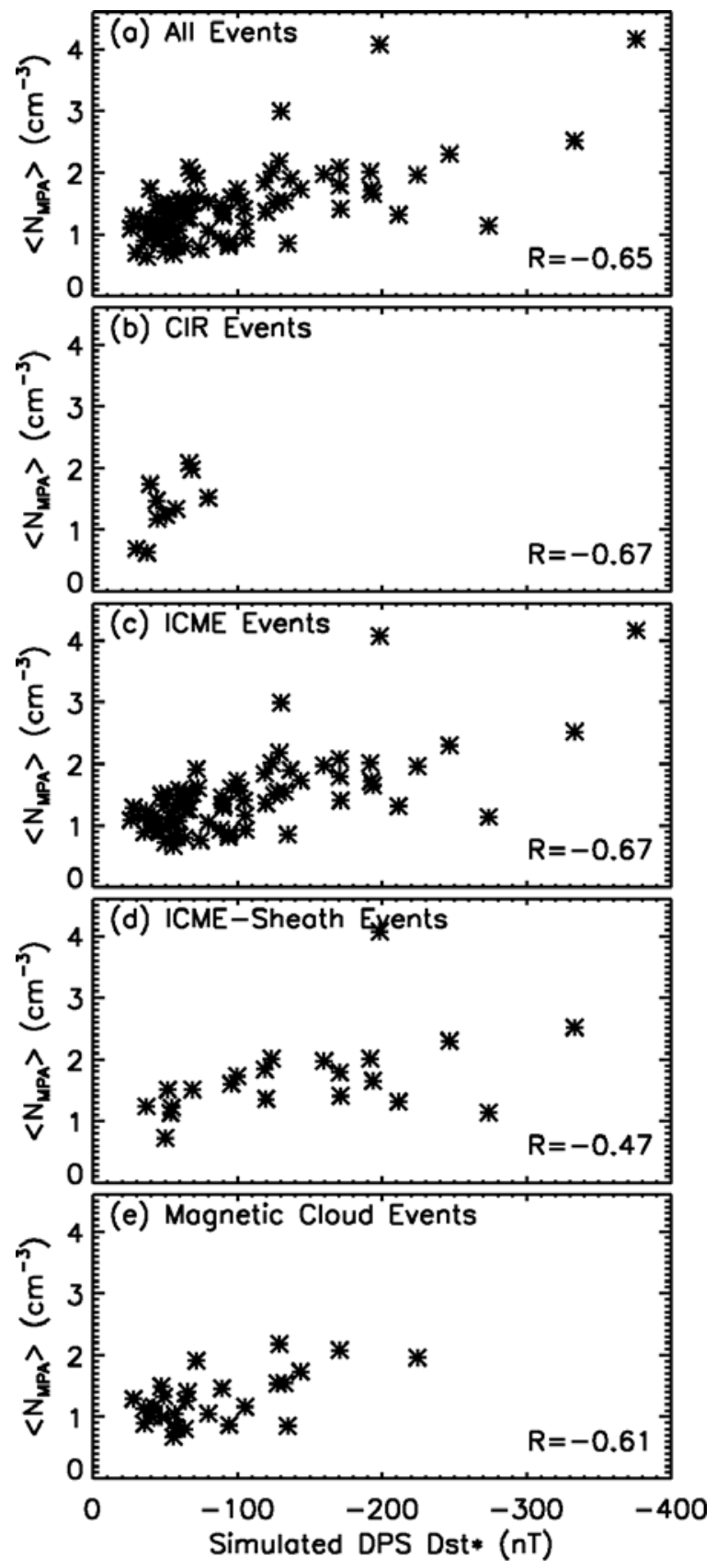

Figure 10. (a-e) Like Figure 7 except that the scatterplots are between the 12-h averaged nightside plasma sheet density and the simulated DPS ${ }_{\min }$ for each storm. 

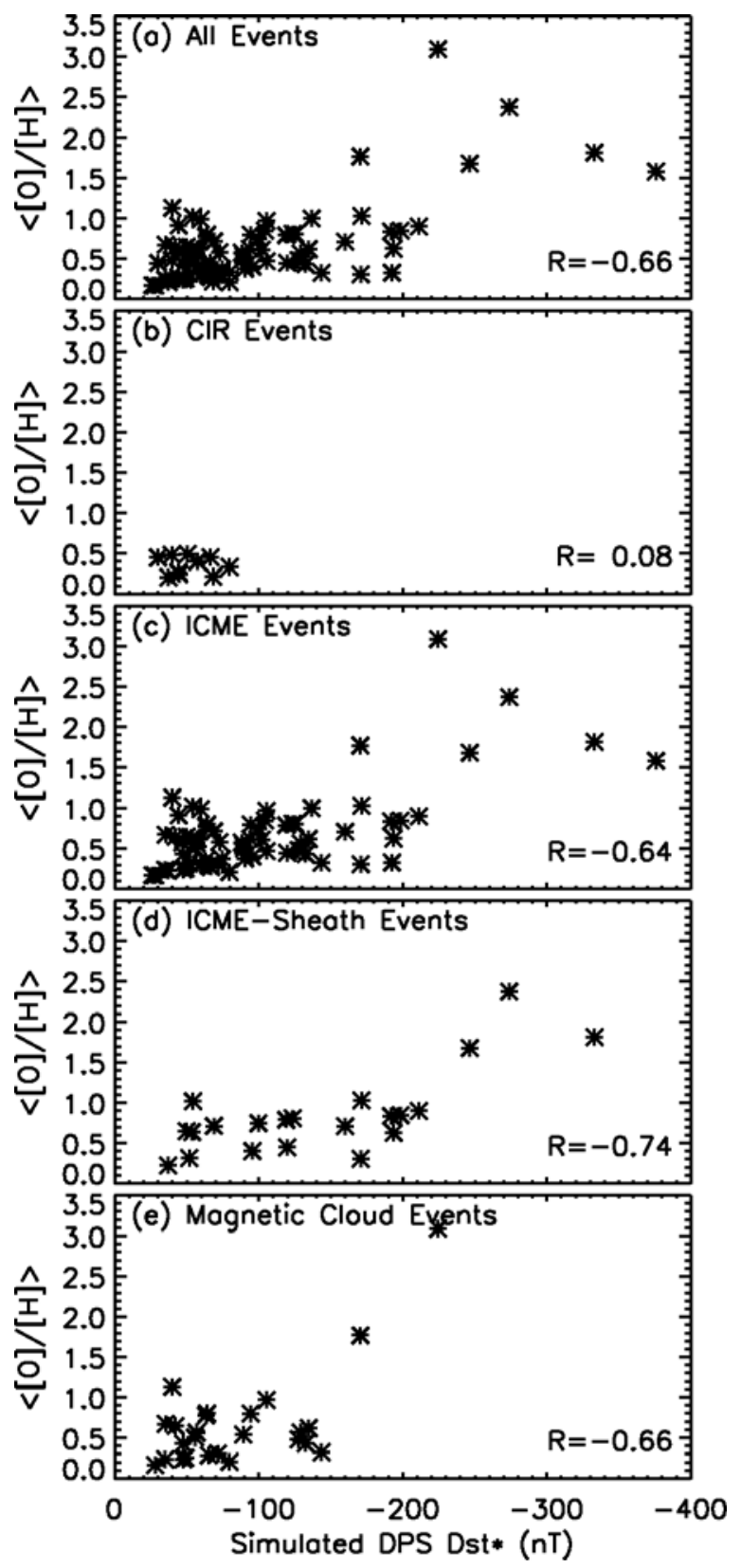

Figure 11. (a-e) Like Figure 7 except that the scatterplots are between the 12 -h averaged $\mathrm{O}^{+}$-to- $\mathrm{H}^{+}$density ratio and simulated DPS ${ }_{\min }$ for each storm.

a large supply of $\mathrm{O}^{+}$is necessary to produce a very intense storm from this version of HEIDI. Furthermore, this cutoff does not seem to depend on storm driver type, as all of the categories show a dramatic shift in compositional dependence near a $\mathrm{DPS}_{\min }$ of $-200 \mathrm{nT}$ (again, except CIR-driven storms, which have no events this large).

[47] All of these driver parameters can be combined into a single input function $I$, defined in this study as the product of the Maynard and Chen activity parameter and the compositionally corrected nightside MPA density. A scatterplot of the 12-h average of $I$ against DPS $_{\min }$ is shown in Figure 12. It is seen that this combination yields the highest correlation coefficients, approaching linearity for some storm categories. That is, this rough estimate of the ring current input yields a very good match with the resulting ring current peak intensity (similar to the finding of Thomsen et al. [1998]). All but one of the storms with DPS $_{\text {min }}<-200 \mathrm{nT}$ have an $\langle I\rangle$ value of greater than 4 (across all storm categories). Therefore, all of the factors together yield the best correlation with the simulation results, demonstrating that all of these factors are indeed necessary to produce a strong ring current.

[48] Of course, other factors are also important, even though they were not included in the input function discussed above. For instance, plasma sheet temperature controls the amount of magnetic drift that the particles will
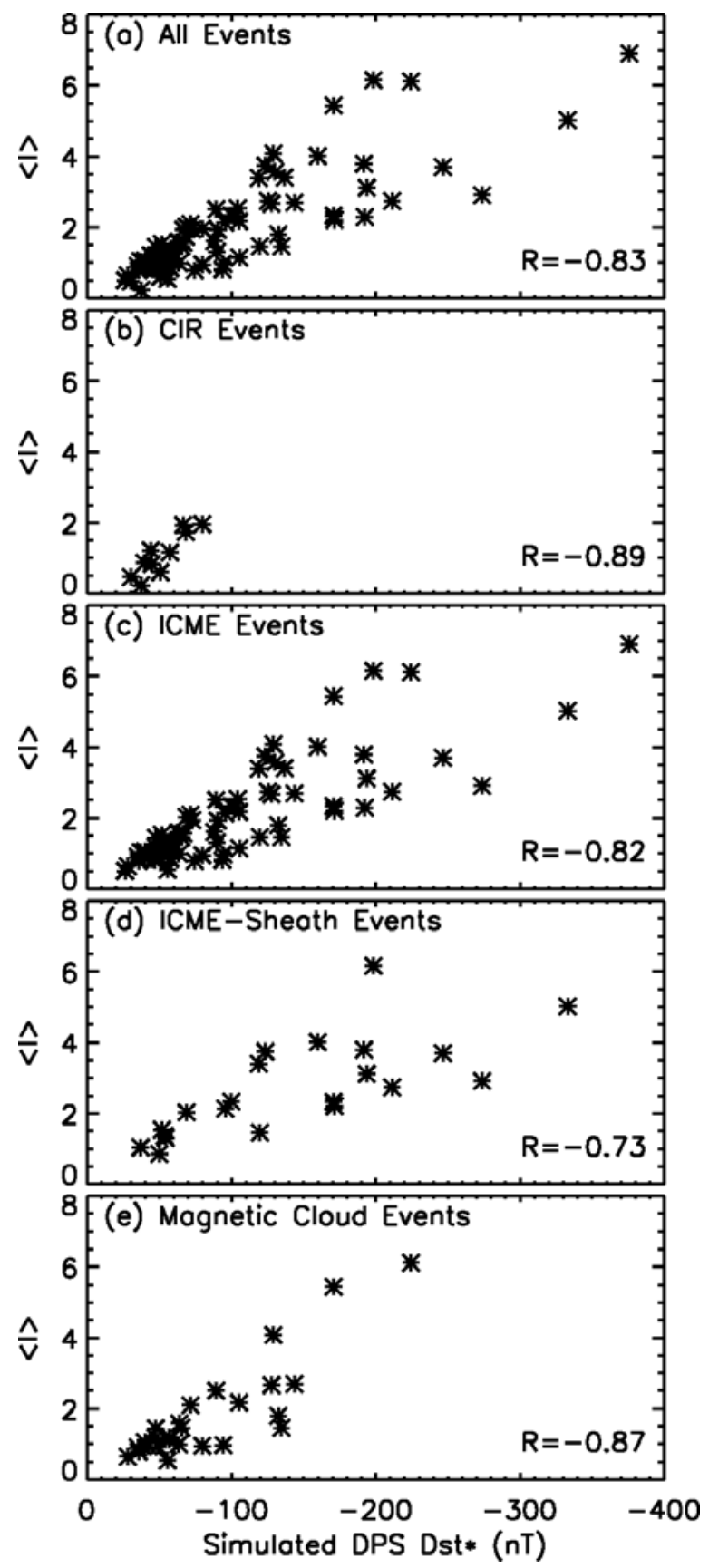

Figure 12. (a-e) Like Figure 7 except that the scatterplots are between the 12-h averaged input function $I$ and simulated DPS ${ }_{\text {min }}$ for each storm. 

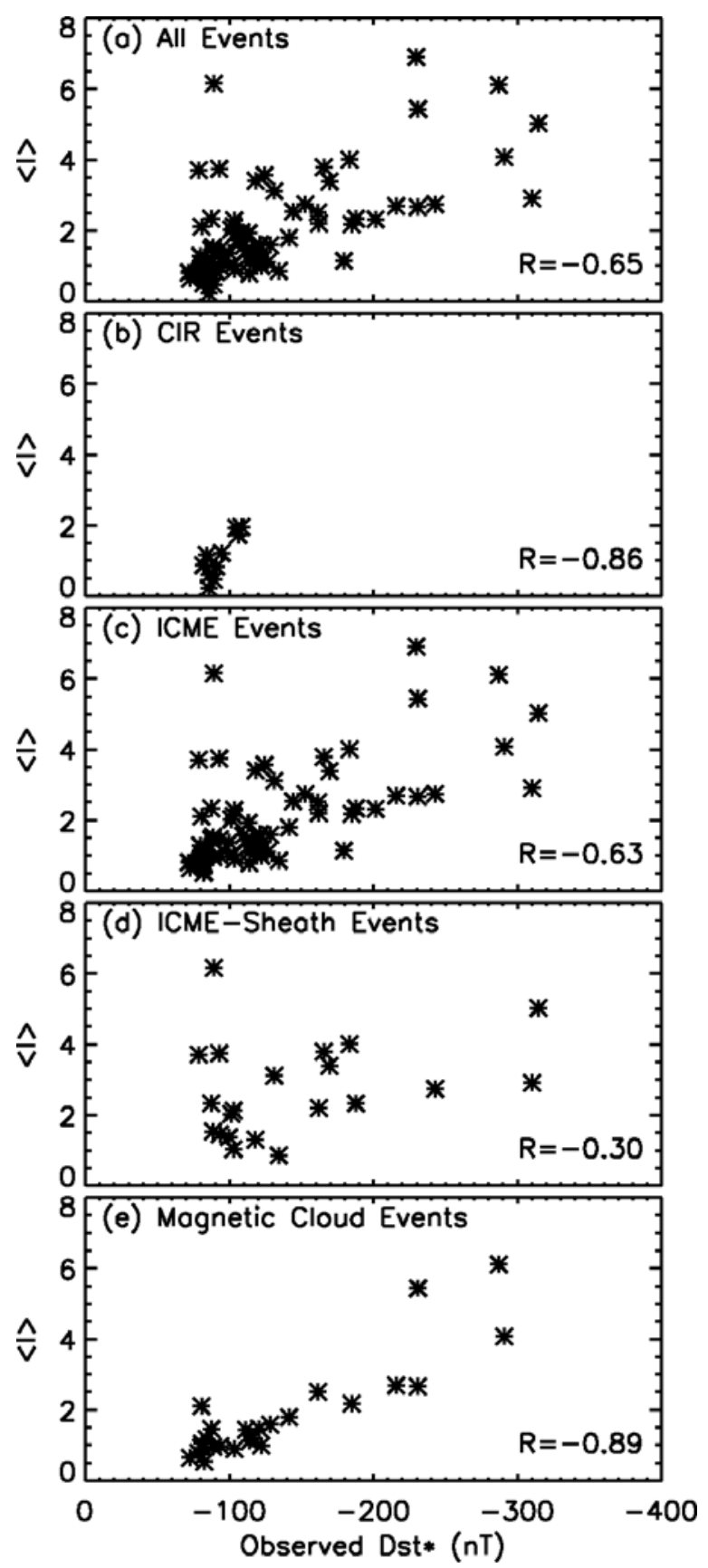

Figure 13. (a-e) Like Figure 7 except that the scatterplots are between the 12-h averaged input function $I$ and observed $D s t^{*}{ }_{\min }$ for each storm. experience in the nearly dipolar inner magnetosphere, and if the initial ion population is too hot, it will azimuthally drift around near geosynchronous orbit and not contribute to a strong ring current. However, as shown in Table 5, the correlation coefficients were all relatively small for $\left\langle\mathrm{T}_{\mathrm{MPA}}\right\rangle$ compared with $\mathrm{DPS}_{\min }$, implying that this parameter is, in general, not a major contributor relative to the other factors considered in this study.

\subsection{Dst* Compared With the Drivers}

[49] It is to be expected that an input function could be devised from the driving parameters that correlates very well with $\mathrm{DPS}_{\text {min }}$, as $\mathrm{DPS}_{\text {min }}$ is a quantity calculated from these input parameters. An interesting question to ask is whether $D s t^{*}{ }_{\min }$, the observed peak intensity of each storm, also correlates well with this input function. Because $\mathrm{DPS}_{\text {min }}$

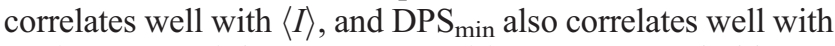
$D s t^{*}{ }_{\min }$, one might expect a transitive property to hold.

[50] Figure 13 shows the scatterplot between the 12-h averaged input function $\langle I\rangle$ and the observed $D s t^{*}{ }_{\text {min }}$ for each storm. The correlation coefficients are not as high as those for $\mathrm{DPS}_{\mathrm{min}}$, but most of them are still above the $5 \%$ level for statistical significance. That is, this roughly calculated input function is a good estimate of the resulting storm intensity. Exactly as with DPS $_{\text {min }}$, all but one of the storm events with $D s t^{*}{ }_{\min }<-200 \mathrm{nT}$ have an $\langle I\rangle$ value greater than 4 (across all storm categories). That is, a big value of $\langle I\rangle$ is a necessary condition for a very intense magnetic storm.

[51] Table 6 lists the correlation coefficients between $D s t^{*}{ }_{\text {min }}$ and the other input and driver parameters considered in this study. Comparing Tables 5 and 6, the correlation coefficients were higher (i.e., closer to +1 or -1 ) in Table 6 than in Table 5 for $\langle K p\rangle$ and $\langle A\rangle$, but vice versa for the other parameters. The $K p$ and $A$ trends are reasonable because $K p$, like $D s t$, is an index derived from subauroral ground-based magnetometers, and both respond to the solar wind-induced geomagnetic activity. The model results are driven by $A$ (which is a function of $K p$ ), but that is not the only model driver, as discussed in section 6.2. The trends for the other parameters are also reasonable because these parameters are direct drivers of the model and therefore necessarily related to the DPS time series.

\subsection{DPS Compared With the Pressures}

[52] $\mathrm{DPS}_{\min }$ was also compared against the simulated pressures within the inner magnetosphere. The correlations were very high when compared with $P_{\max }$ and $P_{\text {avg }}$, as expected. These pressure quantities are relatively direct

Table 6. Correlation Coefficients Between $D s t^{*}{ }_{\min }$ and Other Parameters

\begin{tabular}{llllllll}
\hline \multicolumn{1}{c}{ Parameter $^{\mathrm{a}}$} & All Events & CIR & ICME & Sheath & MC & Ejection & Complex \\
\hline$\langle K p\rangle$ & -0.693 & -0.557 & -0.691 & -0.546 & -0.813 & -0.738 & -0.832 \\
$\langle A\rangle$ & -0.678 & -0.615 & -0.671 & -0.486 & -0.814 & -0.742 & -0.810 \\
$\left\langle F_{10.7}\right\rangle$ & -0.312 & 0.431 & -0.294 & -0.362 & -0.227 & -0.284 & 0.017 \\
$\left\langle\left[\mathrm{O}^{+}\right] /\left[\mathrm{H}^{+}\right]\right\rangle$ & -0.607 & 0.296 & -0.588 & -0.622 & -0.563 & -0.507 & -0.410 \\
$\left\langle N_{\text {MPA }}\right\rangle$ & -0.318 & -0.569 & -0.318 & 0.055 & -0.682 & -0.362 & -0.661 \\
$\left\langle T_{\text {MPA }}\right\rangle$ & 0.206 & -0.352 & 0.197 & 0.110 & 0.233 & -0.125 & 0.349 \\
$\left\langle N_{\text {corr }}\right\rangle$ & -0.451 & -0.493 & -0.439 & -0.110 & -0.783 & -0.467 & -0.643 \\
$\langle$ Input function $\rangle$ & -0.648 & -0.856 & -0.628 & -0.299 & -0.882 & -0.740 & -0.710 \\
\hline
\end{tabular}

${ }^{\text {a }}$ The listed parameters are being correlated with the $D s t^{*}{ }_{\text {min }}$ value for each event within each class. 

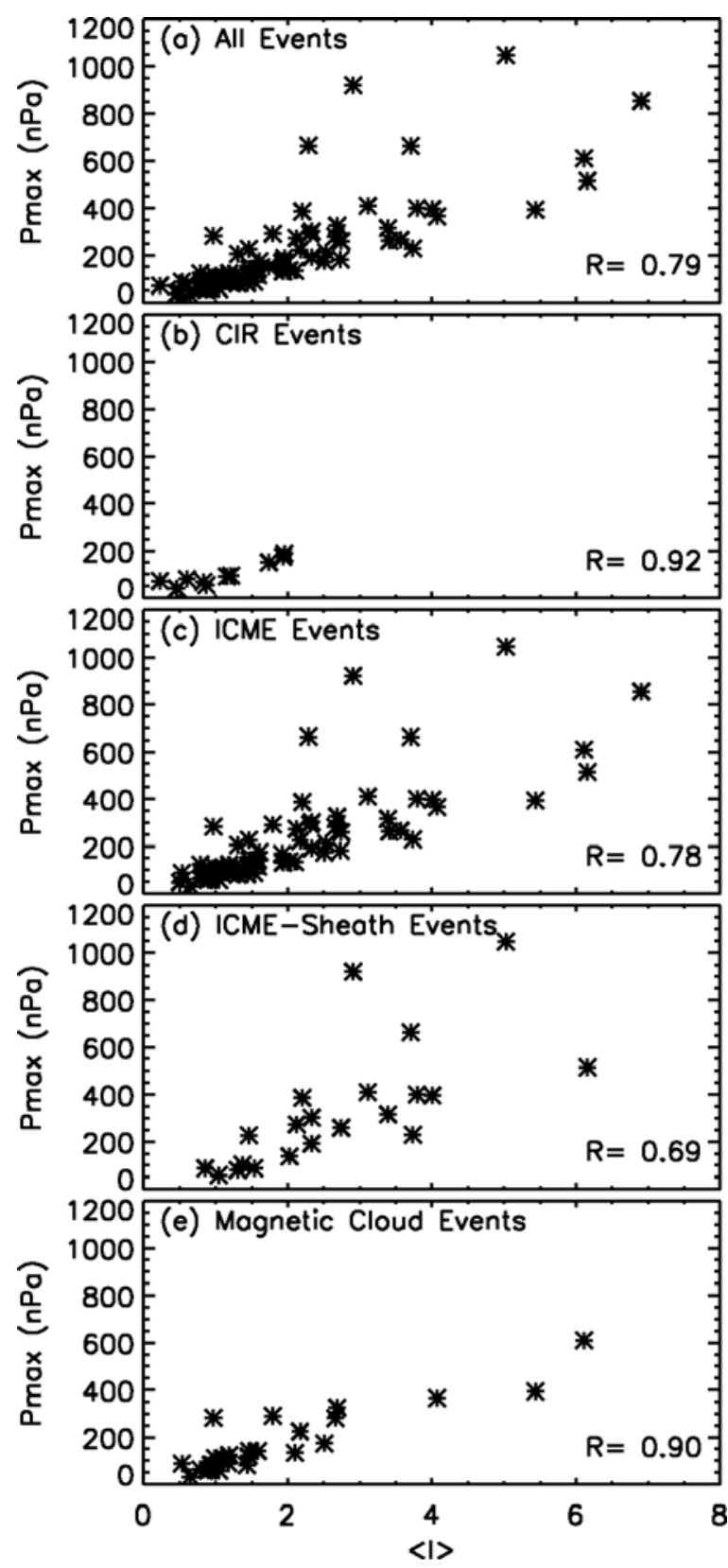

Figure 14. (a-e) Like Figure 7 except that the scatterplots are between the modeled maximum hot ion $\left(\mathrm{H}^{+}\right.$plus $\left.\mathrm{O}^{+}\right)$ pressure and the 12-h averaged input function $I$.

indicators of the total plasma energy content, which is the value used in the DPS equation.

[53] The correlation coefficients were low, however, for the 2 pressure ratio quantities. These pressure ratios are a measure of the local time asymmetry of the resulting ring current. As seen in Table 2, all of the storm categories have a $\Delta \mathrm{P} / \mathrm{P}_{\text {avg }}$ value of roughly 2 . This is also expected, as all of the simulations used the same analytical electric field description, and therefore the plasma morphology within the inner magnetosphere is very similar in all of the storm simulation results. These pressure ratios are a direct result of the plasma morphology, and thus the ratios are roughly similar regardless of storm size or storm category.
[54] It is useful to examine the relationship between these pressure quantities and $\langle I\rangle$. The delivery of plasma to the inner magnetosphere should influence the resulting pressure morphology, and not just the overall, integrated intensity. Figure 14 shows a scatterplot between $P_{\max }$ and $\langle I\rangle$ for five of the storm categories. It is seen that all of the storm categories yield high correlation coefficients. However, the $R$ value for the ICME-sheath-driven storm category is somewhat lower than that for the CIR-driven or magnetic cloud-driven classes. This is related to the steadiness of the driving conditions during each of these types of events. The sheath-driven storms typically experience large fluctuations in their solar wind driving conditions, with a standard sheath passage giving rise to multiple turnings of IMF $B_{z}$ (from southward to northward and back again) and large solar wind density enhancements and dropouts. Such fluctuations are not well captured by the 3-h $K p$ index or by the near-Earth plasma sheet density (deep within the magnetosphere). Sometimes the solar wind fluctuations are captured by these two data sets, as seen in Figure 1, resulting in a simulated double-ring current during the main phase of that storm (15 May 1997). These multiple injections and double-ring currents complicate the relationship between $\langle I\rangle$ and the resulting maximum of the hot ion pressure in the inner magnetosphere.

[55] A final relationship to consider is that between the pressure ratio (i.e., ring current asymmetry) and $\langle I\rangle$. Figure 15 shows a scatterplot of these quantities for 5 of the storm categories. The correlations are all statistically insignificant, with an essentially flat ratio averaging to about 2 for all storm classes. Even though the sheath-driven storm category had by far the largest values for $P_{\max }$ and $P_{\text {avg }}$, it is indistinguishable from the others in terms of ring current local time asymmetry. One might have expected sheathdriven storms to have a higher asymmetry than other categories, as the increased intensity might have meant a change in the plasma morphology. Furthermore, the relationship between $P_{\max }$ and $\langle I\rangle$ was different (slightly lower) for sheath-driven storms. These plots indicate that nothing of the sort exists in these simulation results. The $K p$-driven Volland-Stern electric field yields the same asymmetry regardless of storm size or solar wind driver.

\subsection{Caveats to the Results of This Study}

[56] There are several cautionary limitations to the results of this study that need to be mentioned. The first and foremost is that this study used a simplistic electric and magnetic field description in the model setup, and the real electric and magnetic configuration at any time during any of the storms could very well look dramatically different from the assumed conditions. While there have been studies that find a Volland-Stern electric field to be a good descriptor of the inner magnetospheric electric field [e.g., Korth et al., 1999; Friedel et al., 2001; Jordanova et al., 2003a; Thomsen, 2004; Liemohn et al., 2006], others have found it to be not as good as more sophisticated methods [e.g., Jordanova et al., 1999, 2003b; Ganushkina et al., 2001, 2005; Liemohn et al., 2006]. Similarly, while a dipole magnetic field has worked well for many inner magnetospheric studies [e.g., Ebihara and Ejiri, 1998; Jordanova et al., 2001, 2003a, 2003b; Liemohn et al., 1999, 2006], other studies have shown it to be a poor representation during 

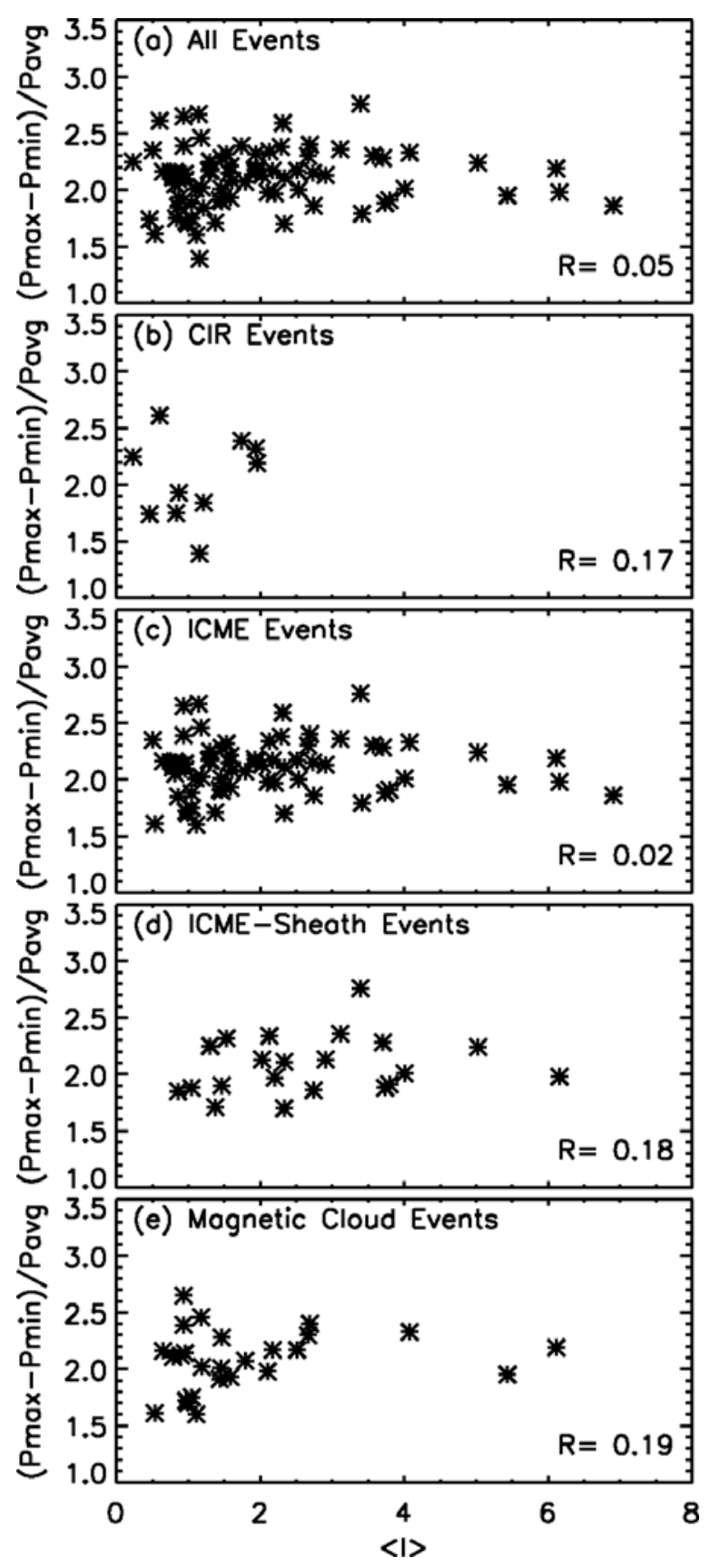

Figure 15. (a-e) Like Figure 7 except that the scatterplots are between the modeled asymmetry of the hot ion pressure $\left(\Delta P / P_{\text {avg }}\right)$ and the 12-h averaged input function $I$.

extreme events [e.g., Tsyganenko et al., 2003; Chen et al., 2005, 2006; Zaharia et al., 2005, 2006; Ganushkina et al., 2006]. What the present study adds to this discussion regarding the dependence on the electric and magnetic field is that for sheath-driven storms, a dipole magnetic field and VollandStern two-cell electric potential pattern is quite reasonable, while for CIR or magnetic cloud-driven storms these may not be the best choices for these field specifications.

[57] Another limitation is that the only data set used for comparison with the model results was $D s t^{*}$, the modified Dst index. While this is supposed to be a good representation of the globally averaged magnetic perturbation from
near-Earth currents, especially the ring current [e.g., Carovillano and Siscoe, 1973; Mayaud, 1980], this index is far from perfect. Liemohn and Kozyra [2003] discussed in detail a number of these contributors, in particular the tail current, the substorm current wedge, and ionospheric currents. Numerous studies have concluded, however, that over $75 \%$ of $D s t^{*}$ is from the inner magnetospheric ring current during intense storm events $(D s t<-100 \mathrm{nT})$ [e.g., Greenspan and Hamilton, 2000; Turner et al., 2000, 2001; Jorgensen et al., 2001; Ganushkina et al., 2002; Liemohn, 2003].

[58] Even though $D s t^{*}$ is the only data used in this study, it should be pointed out that there are other, much better, models for predicting the Dst time series. The models of O'Brien and McPherron [2000] and Temerin and Li [2002, 2006] are notable for their very high prediction efficiencies. The model of Temerin and $L i$ [2006], for instance, has a prediction efficiency of over $95 \%$ for times when Dst is below $-100 \mathrm{nT}$ (that is, during the peaks of intense storms). However, these tools are not physics-based ring current models, but rather ordinary differential equation solutions for Dst itself. While physical meaning can be inferred from the resulting empirically determined coefficients in these models, they do not directly solve the drift equations for the hot ions in the inner magnetosphere. The two forms of models are distinctly different and complementary.

[59] There are other caveats to consider as well. One is that this study only considered intense storm events, those with $D s t_{\min }<-100 \mathrm{nT}$. A different conclusion might be drawn if smaller storm events are also included in the simulation run set. Another is that only a few driving parameters were considered, and all of these were taken as an average for a 12-h interval prior to the time of $D s t^{*}{ }_{\text {min }}$. Again, a different set of conclusions might be drawn if a different set of input parameters were considered, or even a different time interval for these same input parameters.

[60] Regarding all of these caveats, it should be noted that this study is the first of its kind. No other study has taken a ring current simulation code and conducted runs for all of the intense storm events for a full solar cycle. This is just the beginning, and additional simulation run sets with more sophisticated model configurations are planned for the near future.

\section{Summary}

[61] All of the intense magnetic storms (Dst $t_{\min } \leq$ -100 nT) during solar cycle 23 (1996-2005 inclusive) were simulated with the Hot Electron and Ion Drift Integrator (HEIDI) ring current model. Simplistic yet reliable electric and magnetic field descriptions were employed, along with a realistic plasma outer boundary condition based on geosynchronous orbit observations of the nightside, nearEarth plasma sheet. The results for all 90 storm intervals were compared against the observed $D s t^{*}$ time series for each event, as well as numerous input parameters known to be drivers of the ring current intensity. The storms were categorized according to their solar wind driver type (as specified by Zhang et al. [2007b, 2007c]) and the statistics of the datamodel and driver-response comparisons were examined.

[62] The findings from this analysis are summarized as follows: 
[63] 1. Several types of ring current morphologies can arise during magnetic storms, including double ring distributions and an overlaid partial and symmetric ring current, because of the timing and intensity of multiple injections during the main phase of the storm.

[64] 2. This configuration of HEIDI works well for ICME-sheath-driven storm events, implying that the intensity of the inner magnetospheric electric field matches this analytical formulation for this type of storm.

[65] 3. This configuration of HEIDI consistently underpredicts the storm intensity for all other storm categories, implying that, for storms other than those driven by sheath regions of ICMEs, either the intensity of the inner magnetospheric electric field is underestimated by the Volland-Stern model or the observed plasma sheet boundary conditions are systematically missing some of the incoming plasma (possibly because of the assumed composition). It was particularly low for CIR and magnetic cloud-driven storms.

[66] 4. Up to a certain storm intensity level (simulated $\mathrm{DPS}_{\min }$ value of around $-75 \mathrm{nT}$ ), the $K p$ index (averaged over the main phase) is well correlated with the eventual storm intensity, but above this threshold, $K p$ is uncorrelated with the eventual storm intensity. This was true for all storm driver categories.

[67] 5. Plasma sheet density (averaged over the main phase) is a better indicator of eventual storm intensity than $\langle K p\rangle$, but still not exceptionally strong.

[68] 6. Plasma sheet composition (averaged over the main phase) was uncorrelated with eventual storm intensity until a DPS $_{\min }$ value of around $-170 \mathrm{nT}$, and the $\mathrm{O}^{+}-$to- $-\mathrm{H}^{+}$ density ratio was nearly always less than one for storms in this range. For larger storms within the intense range (i.e., DPS $_{\text {min }}<-200 \mathrm{nT}$ ), the average $\mathrm{O}^{+}$-to- $\mathrm{H}^{+}$ratio was nearly always above unity during the main phase. This was true regardless of storm driver category.

[69] 7. A rough input function of the Maynard and Chen [1975] activity parameter (controlling convection strength) multiplied by the nightside plasma sheet density (corrected for composition, as in the work by Liemohn et al. [1999]) is a very good indicator of eventual storm size for all storm driver categories (simulated and observed storm intensity).

[70] 8. The local time asymmetry of the ring current was not dependent on storm intensity or driving structure, and instead is simply determined by the electric field pattern of the Volland-Stern electric field model used in the simulations.

[71] The logical next step is to repeat the exercise with additional model configurations, and with additional data sets for comparison, in order to determine the best fit model setup for each storm driver category. This study showed that sheath-driven storms are well suited for simulation with a simplistic electric and magnetic field model, while this model underestimated other storm classes (notably CIR and magnetic cloud-driven events). Probing the physical processes governing the inner magnetosphere for these other storm classes is an interesting subject for future work.

[72] Acknowledgments. Funding for this study was provided by the National Science Foundation under grants ATM-0402163 and ATM0455727 and by NASA under grants NNGG05GE02G, NNG05GM48G, and NNG05GJ89G. The authors thank Vernon Butler and Matt Onderlinde for additional support in setting up the ring current simulations. The authors also thank all of the data providers for this study, in particular, M. Thomsen and G. Reeves at LANL, the Kyoto World Data Center for the Dst and $K p$ indices, and CDAWeb for the solar wind observations.

[73] Zuyin Pu thanks Geoffrey Reeves and Michael Temerin for their assistance in evaluating this paper.

\section{References}

Alexeev, I. I., E. S. Belenkaya, V. V. Kalegaev, Y. I. Feldstein, and A. Grafe (1996), Magnetic storms and magnetotail currents, J. Geophys. Res., 101, 7737, doi:10.1029/95JA03509.

Bame, S. J., et al. (1993), Magnetospheric plasma analyzer for spacecraft with constrained resources, Rev. Sci. Instrum., 64, 1026, doi:10.1063/ 1.1144173 .

Belian, R. D., G. R. Gisler, T. Cayton, and R. Christensen (1992), High-Z energetic particles at geosynchronous orbit during the great solar proton event series of October 1989, J. Geophys. Res., 97, 16,897, doi:10.1029/ 92JA01139.

Borovsky, J. E., and M. H. Denton (2006), Differences between CMEdriven storms and CIR-driven storms, J. Geophys. Res., 111, A07S08, doi:10.1029/2005JA011447.

Carovillano, R. L., and G. L. Siscoe (1973), Energy and momentum theorems in magnetospheric processes, Rev. Geophys., 11, 289, doi:10.1029/RG011i002p00289.

Chen, M. W., M. Schulz, G. Lu, and L. R. Lyons (2003), Quasi-steady drift paths in a model magnetosphere with AMIE electric field: Implications for ring current formation, J. Geophys. Res., 108(A5), 1180, doi:10.1029/ 2002JA009584.

Chen, M. W., M. Schulz, S. Liu, G. Lu, L. R. Lyons, M. El-Alaoui, and M. Thomsen (2005), Simulated stormtime ring-current magnetic field produced by ions and electrons, in Inner Magnetosphere Interactions: New Perspective From Imaging, Geophys. Monogr. Ser., vol. 159, edited by J. Burch, M. Schulz, and H. Spence, p. 237, AGU, Washington, D.C.

Chen, M. W., S. Liu, M. Schulz, J. L. Roeder, and L. R. Lyons (2006), Magnetically self-consistent ring current simulations during the 19 October 1998 storm, J. Geophys. Res., 111, A11S15, doi:10.1029 2006JA011620.

Daglis, I. A., J. U. Kozyra, Y. Kamide, D. Vassiliadis, A. S. Sharma, M. W. Liemohn, W. D. Gonzalez, B. T. Tsurutani, and G. Lu (2003), Intense space storms: Critical issues and open disputes, J. Geophys. Res., 108(A5), 1208, doi:10.1029/2002JA009722.

Denton, M. H., M. F. Thomsen, H. Korth, S. Lynch, J.-C. Zhang, and M. W. Liemohn (2005), Bulk plasma properties at geosynchronous orbit, J. Geophys. Res., 110, A07223, doi:10.1029/2004JA010861.

Denton, M. H., J. E. Borovsky, R. M. Skoug, M. F. Thomsen, B. Lavraud, M. G. Henderson, R. L. McPherron, J. C. Zhang, and M. W. Liemohn (2006), Geomagnetic storms driven by ICME- and CIR-dominated solar wind, J. Geophys. Res., 111, A07S07, doi:10.1029/2005JA011436.

Dessler, A. J., and E. N. Parker (1959), Hydromagnetic theory of geomagnetic storms, J. Geophys. Res., 64, 2239, doi:10.1029/JZ064i012p02239.

Ebihara, Y., and M. Ejiri (1998), Modeling of solar wind control of the ring current buildup: A case study of the magnetic storms in April 1997, Geophys. Res. Lett., 25, 3751, doi:10.1029/1998GL900006.

Ebihara, Y., and M. Ejiri (2000), Simulation study on fundamental properties of the storm-time ring current, J. Geophys. Res., 105(A7), 15,843, doi:10.1029/1999JA900493.

Farrugia, C. J., et al. (2002), Wind and ACE observations during the great flow of 1-4 May 1998: Relation to solar activity and implications for the magnetosphere, J. Geophys. Res., 107(A9), 1240, doi:10.1029/ 2001JA000188.

Fok, M.-C., J. U. Kozyra, A. F. Nagy, C. E. Rasmussen, and G. V. Khazanov (1993), A decay model of equatorial ring current and the associated aeronomical consequences, J. Geophys. Res., 98, 19,381, doi:10.1029/93JA01848.

Fok, M.-C., T. E. Moore, J. U. Kozyra, G. C. Ho, and D. C. Hamilton (1995), Three-dimensional ring current decay model, J. Geophys. Res., 100(A6), 9619, doi:10.1029/94JA03029.

Friedel, R. H. W., H. Korth, M. G. Henderson, M. F. Thomsen, and J. D. Scudder (2001), Plasma sheet access to the inner magnetosphere, J. Geophys. Res., 106, 5845, doi:10.1029/2000JA003011.

Fu, S. Y., B. Wilken, Q. G. Zong, and Z. Y. Pu (2001), Ion composition variations in the inner magnetosphere: Individual and collective storm effects in 1991, J. Geophys. Res., 106, 29,683, doi:10.1029/2000JA900173.

Fu, S. Y., Q. G. Zong, T. A. Fritz, Z. Y. Pu, and B. Wilken (2002), Composition signatures in ion injections and its dependence on geomagnetic conditions, J. Geophys. Res., 107(A10), 1299, doi:10.1029/ 2001JA002006.

Ganushkina, N. Y., et al. (2000), Entry of plasma sheet particles into the inner magnetosphere as observed by Polar/CAMMICE, J. Geophys. Res., 105, 25,205, doi:10.1029/2000JA900062. 
Ganushkina, N. Y., T. I. Pulkkinen, V. F. Bashkirov, D. N. Baker, and X. Li (2001), Formation of intense nose structures, Geophys. Res. Lett., 28 , 491, doi:10.1029/2000GL011955.

Ganushkina, N. Y., T. I. Pulkkinen, M. V. Kubyshkina, H. J. Singer, and C. T. Russell (2002), Modeling the ring current magnetic field during storms, J. Geophys. Res., 107(A7), 1092, doi:10.1029/2001JA900101.

Ganushkina, N. Y., T. I. Pulkkinen, and T. Fritz (2005), Role of substormassociated impulsive electric fields in the ring current development during storms, Ann. Geophys., 23, 579.

Ganushkina, N., T. I. Pulkkinen, M. Liemohn, and A. Milillo (2006), Evolution of the proton ring current energy distribution during 21-25 April 2001 storm, J. Geophys. Res., 111, A11S08, doi:10.1029/2006JA011609.

Garner, T. W., R. A. Wolf, R. W. Spiro, W. J. Burke, B. G. Fejer, S. Sazykin, J. L. Roeder, and M. R. Hairston (2004), Magnetospheric electric fields and plasma sheet injection to low L-shells during the 4-5 June 1991 magnetic storm: Comparison between the Rice Convection Model and observations, J. Geophys. Res., 109, A02214, doi:10.1029/ 2003JA010208.

Goldstein, J., J. L. Burch, B. R. Sandel, S. B. Mende, P. C. Brandt, and M. R. Hairston (2005), Coupled response of the inner magnetosphere and ionosphere on 17 April 2002, J. Geophys. Res., 110, A03205, doi:10.1029/2004JA010712.

Gonzalez, W. D., E. Echer, A. L. Clua-Gonzalez, and B. T. Tsurutan (2007), Interplanetary origin of intense geomagnetic storms (Dst $<$ 100 nT) during solar cycle 23, Geophys. Res. Lett., 34, L06101, doi:10.1029/2006GL028879.

Gosling, J. T., D. J. McComas, J. L. Phillips, and J. Bame (1991), Activity associated with earth passage of interplanetary shock disturbances and coronal mass ejections, J. Geophys. Res., 96, 7831, doi:10.1029/ 91JA00316

Greenspan, M. E., and D. C. Hamilton (2000), A test of the Dessler-ParkerSckopke relation during magnetic storms, J. Geophys. Res., 105, 5419 , doi:10.1029/1999JA000284

Gurgiolo, C., B. R. Sandel, J. D. Perez, D. G. Mitchell, C. J. Pollock, and B. A. Larsen (2005), Overlap of the plasmasphere and ring current: Relation to subauroral ionospheric heating, J. Geophys. Res., 110 A12217, doi:10.1029/2004JA010986.

Huang, C.-L., H. Spence, J. Lyon, F. Toffoletto, H. Singer, and S. Sazykin (2006), Storm-time configuration of the inner magnetosphere: LFM MHD code, Tsyganenko model, and GOES observations, J. Geophys Res., 111, A11S16, doi:10.1029/2006JA011626.

Huttunen, K. E. J., and H. E. J. Koskinen (2004), Importance of post-shock streams and sheath region as drivers of intense magnetospheric storms and high-latitude activity, Ann. Geophys., 22, 1729.

Huttunen, K. E. J., H. E. J. Koskinen, and R. Schwenn (2002), Variability of magnetospheric storms driven by different solar wind perturbations, J. Geophys. Res., 107(A7), 1121, doi:10.1029/2001JA900171.

Ilie, R., M. W. Liemohn, M. F. Thomsen, J. E. Borovsky, and J.-C. Zhang (2008), Influence of epoch time selection when doing superposed epoch analysis on ACE and MPA data, J. Geophys. Res., doi:10.1029 2008JA013241, in press.

Jordanova, V. K. (2006), Modeling the behavior of corotating interaction region driven storms in comparison with coronal mass ejection driven storms, in Recurrent Magnetic Storms: Corotating Solar Wind Streams, Geophys. Monogr. Ser, vol. 167, edited by B. T. Tsurutani et al., p. 319, AGU, Washington, D.C

Jordanova, V. K., L. M. Kistler, J. U. Kozyra, G. V. Khazanov, and A. F. Nagy (1996), Collisional losses of ring current ions, J. Geophys. Res., 101, 111, doi:10.1029/95JA02000.

Jordanova, V. K., C. J. Farrugia, J. M. Quinn, R. M. Thorne, K. W. Ogilvie, R. P. Lepping, G. Lu, A. J. Lazarus, M. F. Thomsen, and R. D. Belian (1998), Effect of wave-particle interactions on ring current evolution for January 10-11, 1997: Initial results, Geophys. Res. Lett., 25, 2971, doi:10.1029/98GL00649.

Jordanova, V. K., C. J. Farrugia, J. M. Quinn, R. B. Torbert, J. E. Borovsky, R. B. Sheldon, and W. K. Peterson (1999), Simulation of off-equatorial ring current ion spectra measured by Polar for a moderate storm at solar minimum, J. Geophys. Res., 104, 429.

Jordanova, V. K., L. M. Kistler, C. J. Farrugia, and R. B. Torbert (2001), Effects of inner magnetospheric convection on ring current dynamics: March 10-12, 1998, J. Geophys. Res., 106, 29,705.

Jordanova, V. K., L. M. Kistler, M. F. Thomsen, and C. G. Mouikis (2003a), Effects of plasma sheet variability on the fast initial ring current decay, Geophys. Res. Lett., 30(6), 1311, doi:10.1029/2002GL016576.

Jordanova, V. K., A. Boonsiriseth, R. M. Thorne, and Y. Dotan (2003b), Ring current asymmetry from global simulations using a high-resolution electric field model, J. Geophys. Res., 108(A12), 1443, doi:10.1029/ 2003JA009993.

Jorgensen, A. M., M. G. Henderson, E. C. Roelof, G. D. Reeves, and H. E Spence (2001), Charge exchange contribution to the decay of the ring current, measured by energetic neutral atoms (ENAs), J. Geophys. Res., 106, 1931, doi:10.1029/2000JA000124.

Jorgensen, A. M., H. E. Spence, W. J. Hughes, and H. J. Singer (2004), A statistical study of the global structure of the ring current, J. Geophys. Res., 109, A12204, doi:10.1029/2003JA010090.

Khazanov, G. V., T. S. Newman, M. W. Liemohn, M.-C. Fok, and R. W. Spiro (2003), Self-consistent magnetosphere-ionosphere coupling: Theoretical studies, J. Geophys. Res., 108(A3), 1122, doi:10.1029/ 2002JA009624.

Khazanov, G. V., M. W. Liemohn, M.-C. Fok, T. S. Newman, and A. J. Ridley (2004), Stormtime particle energization with AMIE potentials, J. Geophys. Res., 109, A05209, doi:10.1029/2003JA010186.

Korth, H., M. F. Thomsen, J. E. Borovsky, and D. J. McComas (1999), Plasma sheet access to geosynchronous orbit, J. Geophys. Res., 104, 25,047, doi:10.1029/1999JA900292.

Kozyra, J. U., and M. W. Liemohn (2003), Ring current energy input and decay, Space Sci. Rev., 109, 105, doi:10.1023/B:SPAC. 0000007516.10433.ad.

Kozyra, J. U., M.-C. Fok, E. R. Sanchez, D. S. Evans, D. C. Hamilton, and A. F. Nagy (1998), The role of precipitation losses in producing the rapid early recovery phase of the great magnetic storm of February 1986 , J. Geophys. Res., 103, 6801, doi:10.1029/97JA03330.

Lavraud, B., M. H. Denton, M. F. Thomsen, J. E. Borovsky, and R. H. W. Friedel (2005), Superposed epoch analysis of dense plasma access to geosynchronous orbit, Ann. Geophys., 23(7), 2519.

Le, G., C. T. Russell, and K. Takahashi (2004), Morphology of the ring current derived from magnetic field observations, Ann. Geophys., 22, 1267. Liemohn, M. W. (2003), Yet another caveat to the Dessler-Parker-Sckopke relation, J. Geophys. Res., 108(A6), 1251, doi:10.1029/2003JA009839.

Liemohn, M. W., and J. U. Kozyra (2002), Assessing the importance of convective and inductive electric fields in forming the stormtime ring current, in Sixth International Conference on Substorms, edited by R. M. Winglee, p. 456, Univ. of Wash., Seattle.

Liemohn, M. W., and J. U. Kozyra (2003), Lognormal form of the ring current energy content, J. Atmos. Sol. Terr. Phys., 65, 871, doi:10.1016/ S1364-6826(03)00088-9.

Liemohn, M. W., and J. U. Kozyra (2005), Testing the hypothesis that charge exchange can cause a two-phase decay, in The Inner Magnetosphere: Physics and Modeling, Geophys. Monogr. Ser, vol. 155, edited by T. I. Pulkkinen, N. Tsyganenko, and R. H. W. Friedel, p. 211, AGU, Washington, D.C.

Liemohn, M. W., J. U. Kozyra, V. K. Jordanova, G. V. Khazanov, M. F. Thomsen, and T. E. Cayton (1999), Analysis of early phase ring current recovery mechanisms during geomagnetic storms, Geophys. Res. Lett. 26, 2845, doi:10.1029/1999GL900611.

Liemohn, M. W., J. U. Kozyra, M. F. Thomsen, J. L. Roeder, G. Lu, J. E. Borovsky, and T. E. Cayton (2001), Dominant role of the asymmetric ring current in producing the stormtime Dst*, J. Geophys. Res., 106, 10,883, doi:10.1029/2000JA000326.

Liemohn, M. W., J. U. Kozyra, C. R. Clauer, G. V. Khazanov, and M. F. Thomsen (2002), Adiabatic energization in the ring current and its relation to other source and loss terms, J. Geophys. Res., 107(A4), 1045, doi:10.1029/2001JA000243.

Liemohn, M. W., A. J. Ridley, D. L. Gallagher, D. M. Ober, and J. U. Kozyra (2004), Dependence of plasmaspheric morphology on the electric field description during the recovery phase of the 17 April 2002 magnetic storm, J. Geophys. Res., 109, A03209, doi:10.1029/2003JA010304.

Liemohn, M. W., A. J. Ridley, P. C. Brandt, D. L. Gallagher, J. U. Kozyra, D. G. Mitchell, E. C. Roelof, and R. DeMajistre (2005), Parametric analysis of nightside conductance effects on inner magnetospheric dynamics for the 17 April 2002 storm, J. Geophys. Res., 110, A12S22, doi:10.1029/2005JA011109.

Liemohn, M. W., A. J. Ridley, J. U. Kozyra, D. L. Gallagher, M. F. Thomsen, M. G. Henderson, M. H. Denton, P. C. Brandt, and J. Goldstein (2006), Analyzing electric field morphology through data-model comparisons of the GEM IM/S Assessment Challenge events, J. Geophys. Res., 111, A11S11, doi:10.1029/2006JA011700.

Liemohn, M. W., J. U. Kozyra, A. J. Ridley, M. F. Thomsen, M. G. Henderson, P. C. Brandt, and D. G. Mitchell (2007), Modeling the ring current response to a sawtooth oscillation event, J. Atmos. Sol. Terr Phys., 69, 67, doi:10.1016/j.jastp.2006.07.016.

Liemohn, M. W., J.-C. Zhang, M. F. Thomsen, J. E. Borovsky, J. U. Kozyra, and R. Ilie (2008), Superstorms at geosynchronous orbit: How different are they?, Geophys. Res. Lett., 35, L06S06, doi:10.1029/ 2007GL031717.

Lui, A. T. Y. (2003), Inner magnetospheric plasma pressure distribution and its local time asymmetry, Geophys. Res. Lett., 30(16), 1846, doi:10.1029/ 2003GL017596.

Mayaud, P. N. (1980), Derivation, Meaning, and Use of Geomagnetic Indices, Geophys. Monogr. Ser., vol. 22, AGU, Washington, D.C. 
Maynard, N. C., and A. J. Chen (1975), Isolated cold plasma regions: Observations and their relation to possible production mechanisms, J. Geophys. Res., 80, 1009, doi:10.1029/JA080i007p01009.

Ober, D. M., J. L. Horwitz, and D. L. Gallagher (1997), Formation of density troughs embedded in the outer plasmasphere by subauroral ion drift events, J. Geophys. Res., 102, 14,595, doi:10.1029/97JA01046.

O'Brien, T. P., and R. L. McPherron (2000), An empirical phase space analysis of ring current dynamics: Solar wind control of injection and decay, J. Geophys. Res., 105, 7707, doi:10.1029/1998JA000437.

Ohtani, S., P. C. Brandt, H. J. Singer, D. G. Mitchell, and E. C. Roelof (2006), Statistical characteristics of hydrogen and oxygen ENA emission from the storm-time ring current, J. Geophys. Res., 111, A06209, doi:10.1029/2005JA011201

Pulkkinen, T. I., et al. (2001), Ring current ion composition during solar minimum and rising solar activity: Polar/CAMMICE/MICS results, J. Geophys. Res., 106, 19,131, doi:10.1029/2000JA003036.

Rairden, R. L., L. A. Frank, and J. D. Craven (1986), Geocoronal imaging with Dynamics Explorer, J. Geophys. Res., 91, 13,613, doi:10.1029/ JA091iA12p13613.

Richardson, I. G., et al. (2006), Major geomagnetic storms (Dst $\leq-100$ nT) generated by corotating interaction regions, J. Geophys. Res., 111, A07S09, doi:10.1029/2005JA011476.

Sazykin, S., R. A. Wolf, R. W. Spiro, T. I. Gombosi, D. L. De Zeeuw, and M. F. Thomsen (2002), Interchange instability in the inner magnetosphere associated with geosynchronous particle flux decreases, Geophys. Res. Lett., 29(10), 1448, doi:10.1029/2001GL014416.

Sckopke, N. (1966), A general relation between the energy of trapped particles and the disturbance field near the Earth, J. Geophys. Res., 71, 3125.

Stern, D. P. (1975), The motion of a proton in the equatorial magnetosphere, J. Geophys. Res., 80, 595, doi:10.1029/JA080i004p00595.

Sugiura, M., and T. Kamei (1991), Equatorial Dst index 1957-1986, IAGA Bull., 40, Int. Serv. of Geomagn. Indices, Saint-Maur-des-fosses, France.

Temerin, M., and X. Li (2002), A new model for the prediction of Dst on the basis of the solar wind, J. Geophys. Res., 107(A12), 1472, doi:10.1029/2001JA007532.

Temerin, M., and X. Li (2006), Dst model for 1995-2002, J. Geophys. Res., 111, A04221, doi:10.1029/2005JA011257.

Thomsen, M. F. (2004), Why $K p$ is such a good measure of magnetospheric convection, Space Weather, 2, S11004, doi:10.1029/2004SW000089.

Thomsen, M. F., J. E. Borovsky, D. J. McComas, and M. R. Collier (1998), Variability of the ring current source population, Geophys. Res. Lett., 25, 3481, doi:10.1029/98GL02633.

Tsyganenko, N. A. (1989), A magnetospheric magnetic field model with a warped tail current sheet, Planet. Space Sci., 37, 5, doi:10.1016/00320633(89)90066-4.

Tsyganenko, N. A. (1995), Modeling the Earth's magnetospheric magnetic field confined within a realistic magnetopause, J. Geophys. Res., 100, 5599, doi:10.1029/94JA03193.

Tsyganenko, N. A., H. J. Singer, and J. C. Kasper (2003), Storm-time distortion of the inner magnetosphere: How severe can it get?, J. Geophys. Res., 108(A5), 1209, doi:10.1029/2002JA009808.

Turner, N. E., D. N. Baker, T. I. Pulkkinen, and R. L. McPherron (2000), Evaluation of the tail current contribution to Dst, J. Geophys. Res., 105, 5431, doi:10.1029/1999JA000248.
Turner, N. E., D. N. Baker, T. I. Pulkkinen, J. L. Roeder, J. F. Fennell, and V. K. Jordanova (2001), Energy content in the stormtime ring current J. Geophys. Res., 106, 19,149, doi:10.1029/2000JA003025.

Volland, H. (1973), A semiempirical model of large-scale magnetospheric electric fields, J. Geophys. Res., 78, 171, doi:10.1029/JA078i001p00171.

Wang, Y., C. L. Shen, S. Wang, and P. Z. Ye (2003), An empirical formula relating the geomagnetic storm's intensity to the interplanetary parameters: $-V B_{z}$ and $\Delta t$, Geophys. Res. Lett., 30(20), 2039, doi:10.1029/ 2003GL017901.

Xie, H., N. Gopalswamy, O. C. St. Cyr, and S. Yashiro (2008), Effects of solar wind dynamic pressure and preconditioning on large geomagnetic storms, Geophys. Res. Lett., 35, L06S08, doi:10.1029/2007GL032298.

Young, D. T., H. Balsiger, and J. Geiss (1982), Correlations of magnetospheric ion composition with geomagnetic and solar activity, J. Geophys. Res., 87, 9077, doi:10.1029/JA087iA11p09077.

Zaharia, S., M. F. Thomsen, J. Birn, and M. H. Denton (2005), Effect of storm-time plasma pressure on the magnetic field in the inner magnetosphere, Geophys. Res. Lett., 32, L03102, doi:10.1029/2004GL021491.

Zaharia, S., V. K. Jordanova, M. F. Thomsen, and G. D. Reeves (2006), Self-consistent modeling of magnetic fields and plasmas in the inner magnetosphere: Application to a geomagnetic storm, J. Geophys. Res. 111, A11S14, doi:10.1029/2006JA011619.

Zhang, J.-C., M. W. Liemohn, J. U. Kozyra, B. J. Lynch, and T. H. Zurbuchen (2004), A statistical study on the geoeffectiveness of near-Earth magnetic clouds during high solar activity years, J. Geophys. Res., 109, A09101, doi:10.1029/2004JA010410.

Zhang, J.-C., M. W. Liemohn, M. F. Thomsen, J. U. Kozyra, M. H. Denton, and J. E. Borovsky (2006), A statistical comparison of hot-ion properties at geosynchronous orbit during intense and moderate geomagnetic storms at solar maximum and minimum, J. Geophys. Res., 111, A07206, doi:10.1029/2005JA011559.

Zhang, J.-C., M. W. Liemohn, D. L. De Zeeuw, J. E. Borovsky, A. J. Ridley, S. Sazykin, M. F. Thomsen, J. U. Kozyra, T. I. Gombosi, and R. A. Wolf (2007a), Understanding storm-time ring current sources through data-model comparisons of a moderate storm, J. Geophys. Res., 112, A04208, doi:10.1029/2006JA011846.

Zhang, J., et al. (2007b), Solar and interplanetary sources of major geomagnetic storms (Dst $<-100 \mathrm{nT})$ during 1996-2005, J. Geophys. Res., 112, A10102, doi:10.1029/2007JA012321.

Zhang, J., et al. (2007c), Correction to "Solar and interplanetary sources of major geomagnetic storms (Dst $\leq-100 \mathrm{nT}$ ) during 1996-2005", J. Geophys. Res., 112, A12103, doi:10.1029/2007JA012891.

Zhang, J., W. Poomvises, and I. G. Richardson (2008), Sizes and relative geoeffectiveness of interplanetary coronal mass ejections and the preceding shock sheaths during intense storms in 1996-2005, Geophys. Res. Lett., 35, L02109, doi:10.1029/2007GL032045.

M. Jazowski and M. W. Liemohn, Atmospheric, Oceanic, and Space Sciences Department, University of Michigan, Ann Arbor, MI 48109, USA. (liemohn@umich.edu) 